\title{
The High Mannose Glycans from Bovine Ribonuclease B Isomer Characterization by Ion Trap MS
}

\author{
Justin M. Prien, ${ }^{a}$ David J. Ashline, ${ }^{a}$ Anthony J. Lapadula, \\ Hailong Zhang, ${ }^{a}$ and Vernon N. Reinhold ${ }^{a, b}$ \\ a The Glycomics Center, Division of Molecular, Cellular, and Biomedical Sciences, University of New \\ Hampshire, Durham, New Hampshire, USA \\ ${ }^{b}$ The Glycomics Center, Department of Chemistry, University of New Hampshire, Durham, New \\ Hampshire, USA \\ ${ }^{c}$ The Glycomics Center, Department of Computer Science, University of New Hampshire, Durham, New \\ Hampshire, USA
}

\begin{abstract}
Thirteen high mannose isomers have been structurally characterized within three glycomers, $\mathrm{Man}_{5} \mathrm{GlcNAc}_{2}, \mathrm{Man}_{7} \mathrm{GlcNAc}_{2}$, and $\mathrm{Man}_{8} \mathrm{GlcNAc}_{2}$ released from bovine ribonuclease $\mathrm{B}$, six previously unreported. The study was carried out with a single ion trap instrument involving no chromatography. Three previously characterized isomers from $\mathrm{Man}_{7}$ and $\mathrm{Man}_{8}$ (three each) have been identified plus one unreported $\mathrm{Man}_{7}$ isomer. Incomplete $\alpha$-glucosidase activity on the $\operatorname{Man}_{6}$ and $\mathrm{Man}_{7}$ glycoproteins appears to account for two additional isomeric structures. The preeminence of ion traps for detail analysis was further demonstrated by resolving three new isomers within the $\mathrm{Man}_{5}$ glycomer summing to the six previously unreported structures in this glycoprotein. All reported structures represent a distribution of Golgi processing remnants that fall within the $\mathrm{Man}_{9} \mathrm{GlCNAc}_{2}$ footprint. Topologies were defined by ion compositions along a disassembly pathway while linkage and branching were aided by spectral identity in a small oligomer fragment library. Isomers from this glycoprotein appear to represent a distribution of Golgi processing remnants, and an alphanumeric classification scheme has been devised to identify all products. Although numerous analytical strategies have been introduced to identify selected components of structure, it has been the continued focus of this and previous reports to only build upon protocols that can be integrated into a high throughput strategy consistent with automation. Duplication of these and results from comparable standards could bring an important analytical focus to carbohydrate sequencing that is greatly lacking. (J Am Soc Mass Spectrom 2009, 20, 539-556) @ 2009 American Society for Mass Spectrometry
\end{abstract}

$\mathrm{L}$ acking a definite endpoint for defining a carbohydrate sequence and coupled with the analytical tradition of reporting has developed without established standards. As a consequence, almost any structural inference appears publishable, including presumed biological insight. But, as researchers slowly unravel the details of function, it is becoming apparent that this relaxed form of reporting is inappropriate and the goals of exacting structural detail need to be relentlessly pursued and corroborated. Advances in the determination of structure are directly related to instrumental and technological developments, and for biopolymer sequencing, the mass spectrometer has played a major role. There are numerous adjunct techniques that complement a glycome analysis; however, this

Address reprint requests to Dr. V. N. Reinhold, Gregg Hall, Rm. 440, University of New Hampshire, 35 Colovos Road, Durham, NH 03824, USA. E-mail: vnr@unh.edu array of protocols often complicates a comparative structural evaluation. This can be further confused by applications on a wide assortment of sample types. Such diversity of technologies and applications needs to be focused, contrasted, compared, and brought into general acceptance before we can advance to the more challenging problems of biological function. Since many instrumental components are expensive and technically demanding, comparative evaluations from one laboratory are understandably lacking and it is quite usual to have a single laboratory position an instrumental approach energetically. With that inevitability, an alternative way to evaluate instrument advances or new protocols would be with a series of standard samples which can assess progress and potentially discover new structural features. Recent reports [1-3] have recognized this opportunity and represented protocols with a structural study of the glycans obtained from bovine ribonuclease B (RNase B). Although all glycan samples render the inherent problems of linkage and branching, 
these glycans exhibit an additional complexity of multiple isomers that are often transparent to MS characterization. This observation of isomers is not new, but its prevalence in common structures [4] and extensive presence in a diversity of malignant tissues [5] strongly suggests this component of structure needs greater attention. For a comprehensive glycan analysis, it may be appropriate to reason all possible isomers exist unless proven otherwise.

For a number of years selective strategies and instrumental approaches have been slowly coalescing to better understand oligosaccharide structures. Since the first commercial introduction of ITMS (ion trap mass spectrometer) equipment in 1995, (Finnigan's LCQ and GCQ and Bruker-Franzen's ESQUIRE), we have considered this approach as having the greatest promise for carbohydrate sequencing, and assembled around this technology a number of simple principles and understandings that are summarized here. Foremost: (1) Samples prepared by methylation and reduction position fragments in a glycan array, thus, termini, extending, and branched components of structure can be distinctly placed; (2) Selected pathways of disassembly can define domains of structure providing antennal specificity; (3) Metal ions $\left(\mathrm{Na}^{+}\right)$, enhance sensitivity, fragmentation, and adduct stereo-specifically providing an opportunity to evaluate monomer stereochemistry; (4) Ion pathways that fail to define a single topology are an indicator of structural isomers, which can, in turn, be isolated and characterized; (5) A pathway of disassembly preferentially releases labile residues providing renormalized product spectra with more comparable stability and enhanced detection; (6) Collision energies are effectively enhanced with disassembly, providing greater structural detail upon progression to fewer oligomers, (oscillators); and, (7) a searchable library of fragments anchors the details of disassembly.

Thus, using ion trap $\mathrm{MS}^{n}$, a relational set of fragment ion compositions are corner-stones to structural understanding where each can be simply defined as the sum of methylated monomers plus or minus any mass change due to bond rupture at, or near, a former linkage. We refer to these small mass identifiers as scars, e.g., an open hydroxyl as in C- and Y-ions, or a [1, 2]-pyranene residue characteristic of a B-ion. The ability to profile all ions in a sample glycome coupled with the facility (and need) to dig deep into product fragments and inquire about structure detail generates a wealth of data that requires integrating for sequential meaning. Thus, bioinformatic tools are being built around this understanding, and such tools remain fundamental to handle the copious data. To approach this problem two strategies are being utilized, a spectral library of fragments [6] coupled with software tools to furnish a fragment ion's composition [unpublished]. A second tool [7] also couples changes in ion composition with continuity relationships for each step of an $\mathrm{MS}^{n}$ disassembly pathway. Both tools and the fragment library are guides that focus output to provide discrete structures from multiple possibilities without invoking biological insight, or any other analytical data. In that sense these approaches perform their analyses de novo with a backup option to confirm and search spectral products with the fragment library. We do not have an exacting measure of how comprehensive or generally applicable such tools and ion trap $\mathrm{MS}^{\mathrm{n}}$ will become. With that goal in mind this report is an attempt to contrast recent reports using an accepted biological reference standard, the glycans from bovine RNase B.

\section{Experimental}

\section{Sample Preparation}

$\mathrm{N}$-linked glycans from $2 \mathrm{mg}$ of bovine ribonuclease B (Sigma Aldrich, St. Louis, MO) were released enzymatically following directions from the supplier and the isolated glycans were reduced with sodium borohydride. Methylation was carried out as described [8] and the dried samples re-suspended in aqueous methanol [75\% (vol/vol)] for MS analysis.

\section{Glycan Analysis}

Sequential mass spectra were obtained and contrasted on two ion trap instruments, a high capacity Paul trap (HCTultra PTM Discovery System, Bruker Daltonics, Billerica, MA) and from a linear ion trap (LTQ Thermo Fisher Scientific, Waltham, MA). The Thermo instrument was additionally equipped with a TriVersa Nanomate nanoelectrospray ion source (Advion, Ithaca, NY). Signal averaging was accomplished by adjusting the number of microscans within each scan, generally ranging between 3 and 20 microscans. Collision parameters were left at default values with normalized collision energy set to $35 \%$ or to a value leaving a minimal precursor ion peak. Activation $Q$ was set at 0.25 , and activation time for $30 \mathrm{~ms}$.

\section{Data Analysis}

Initial topology and isomer assignments were made manually. Analyst-selected spectra were matched against a spectral library of permethylated fragments to confirm fragment ion assignments [6]. Ion fragment pathways were selected manually by the analyst and then entered into OSCAR (Oligosaccharide Subtree Constraint Algorithm) to ascertain the compatibility of each pathway with a set of expected isomeric structures [7].

\section{Nomenclature}

The nomenclature used to identify these high mannose glycans has been cumbersome and a more specific notation is sorely needed. The system used by Fu et al., 1994 [9] was based on antennal identification intro- 


\section{Numbering System For High Mannose Isomers}
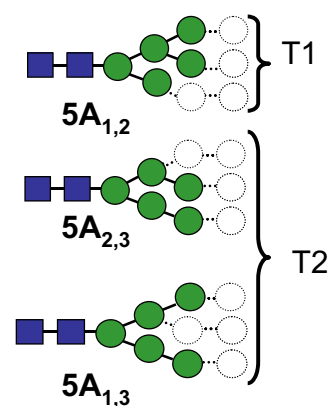

$\mathrm{T} 2$
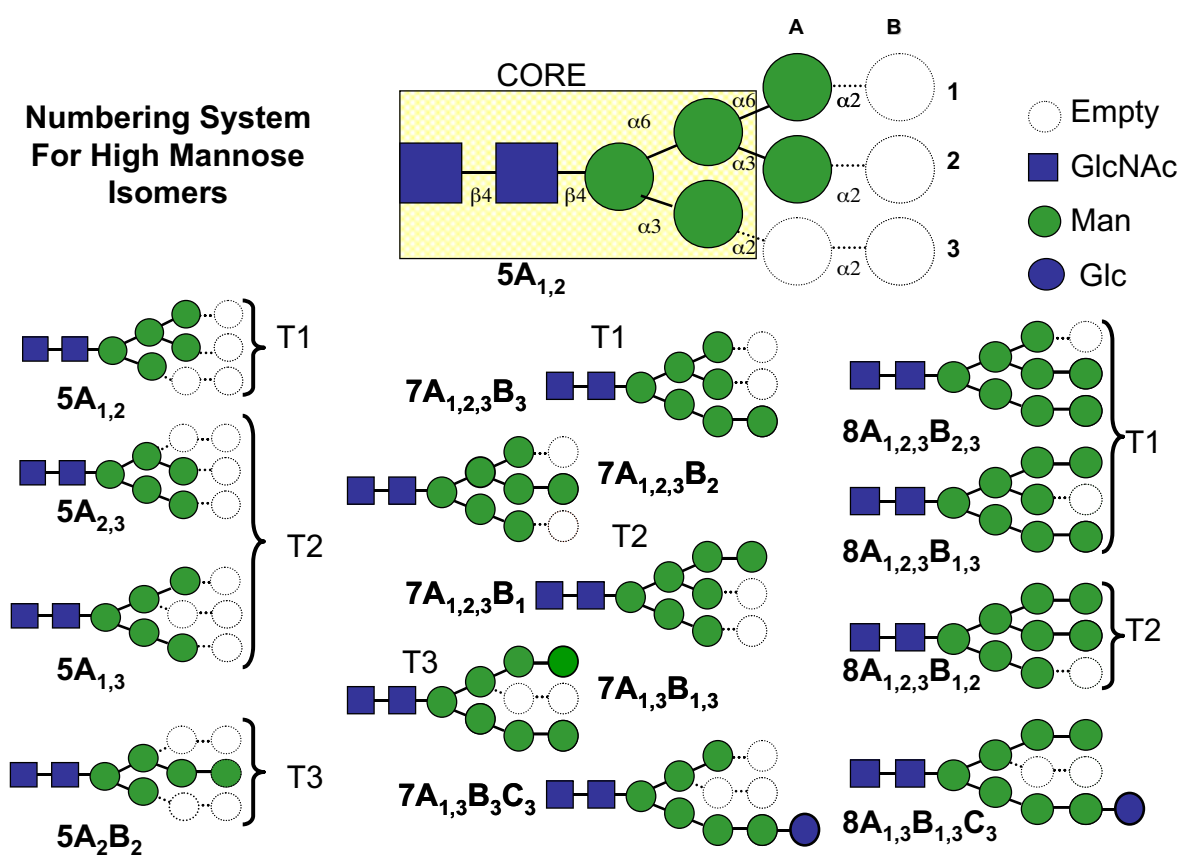

Figure 1. Notation of high mannose glycan processing products as determined by $\mathrm{MS}^{n}$. Template of empty circles for the $\mathrm{Man}_{9} \mathrm{GlcNAc}_{2}$ structure overlaid with detected processing isomers, (filled circles). Center scheme example represents pattern of colors and linkages with N-linked core outlined. Annotation for isomers outside of core region identified as columns A and B with subscript rows 1, 2, and 3. Filled circles depict Man ${ }_{5} \mathrm{GlcNAc}_{2}, 5 \mathrm{~A}_{1,2}$. Structures can be divided into topologies (monomer connectivity) and further subdivided into structural isomers (linkage). Identified $\mathrm{Man}_{5}$ structures include three topologies and four structural isomers: T1 $\left(5 \mathrm{~A}_{1,2}\right) ; \mathrm{T} 2$ $\left(5 \mathrm{~A}_{2,3}, 5 \mathrm{~A}_{1,3}\right)$, and $\mathrm{T} 3\left(5 \mathrm{~A}_{2} \mathrm{~B}_{2}\right)$. For $\mathrm{Man}_{7}$, also includes three topologies and four structural isomers. For $\mathrm{Man}_{8}$ two topologies have been identified that include three structural isomers. Cartoons patterns as introduced, http://glycomics.scripps.edu/CFGnomenclature.pdf

duced by Vliegenthart et al., 1983 [11]. The $\mathrm{Man}_{7}$ isomers were identified as occupying positions on that template, D1, D2, and D3, (terminal positions extending each antenna on Man6 from bottom to top, respectively). This nomenclature was recently extended [1] to include the three $\mathrm{Man}_{8}$ isomers by supplementing double labels for the occupied sites, D1D2, D1D3, and D2D3. Different nomenclature has been introduced to include the two isomer groups, M7-1, M7-2, M7-3 and M8-1, M8-2, and M8-3 [3]. Extension of either notation to represent all processing isomers would not be possible. Thus, introduced here is an alphanumeric notation to specifically identify all processing products, first by ascribing a glycomer number, and second, by occupancy at the six antennal positions beyond the N-linked core, two columns, (A and B) in three rows as subscripts. With this shorthand notation the $\mathrm{Man}_{5} \mathrm{GlcNAc}_{2}$ would be identified as $5 \mathrm{~A}_{1,2}$, while the three isomers of $\mathrm{Man}_{7}$ would be identified as $7 \mathrm{~A}_{1,2,3} \mathrm{~B}_{3}, \mathrm{~A}_{1,2,3} \mathrm{~B}_{2}$, and $7 \mathrm{~A}_{1,2,3} \mathrm{~B}_{1}$. Assuming a uniform biological precursor all isomer products of processing could be classified by this simple scheme, (Figure 1). A key to cartoon symbols, representative structures, and fragment masses are summarized in Table 1. Additional linear notation for a terminal mannose residue (fully methylated) has been indicated with a subscript (( $\mathrm{Man}-)$.

\section{Results}

\section{The Canonical Structure: $\operatorname{Man}_{5} \mathrm{GlcNAc}_{2}\left(5 A_{1,2}\right)$}

The most abundant glycomer to be released from bovine ribonuclease $\mathrm{B}$ has been that of $\mathrm{Man}_{5} \mathrm{GlCNAc}_{2}$ and this structure has been purported to be a single isomer. Sequential MS analysis of this ion, $m / z$ 1595.8, (prepared as the methyl-reduced derivative), was investigated as a routine check on this readily available sample. The acquired data supported the canonical structure, and these $\mathrm{MS}^{\mathrm{n}}$ steps are presented in Figure 2, with pathway summaries in Table 2a, $\left(\mathrm{MS}^{2-6} ; \mathrm{m} / \mathrm{z} 1595.9,1302.6,1084.4,866.4\right.$, and 648.2, spectra, Figure 2a-e). Adjacent to each spectrum is a proposed structure that accounts for the major ion fragments.

When using the above pathway as data input, the output from Composition Finder indicated a consecutive monomer loss of GlcNAcol, (Figure 2a), and three terminal (fully methylated) mannose residues, (Figure 2c-e), as a consequence of simple glycosidic cleavage, (Table 2a). Also, the compositions increased by a single scar for each neutral loss indicating all were branched residues. Loss from a linear topology would show no scar increments. The last pathway ion, $m / z$ 648.2, (Figure 2e), possessed a sodiated $\mathrm{Hex}_{2}$ GlcNAc composition 
Table 1. Key to cartoon symbols and fragment masses as depicted in disassembly pathways.

\begin{tabular}{|c|c|c|c|}
\hline Symbol & Fragment identity & $\begin{array}{c}\text { Neutral loss } \\
\text { (singly-charged } \\
\text { precursor) }\end{array}$ & $\begin{array}{l}\text { Sodiated mass } \\
\qquad[\mathrm{M}+\mathrm{Na}]^{+}\end{array}$ \\
\hline & Terminal Hexose, B-ion & 218 & 241 \\
\hline & Terminal Hexose, C-ion & 236 & 259 \\
\hline & Internal Hexose, $\mathrm{B} / \mathrm{Y}$-ion & 204 & 227 \\
\hline & Internal Hexose, $\mathrm{C} / \mathrm{Y}$-ion & 222 & 245 \\
\hline & Branched Hexose, B/Y/Y-ion & 190 & 213 \\
\hline & Terminal Dihexose, $B_{2}$-ion & 422 & 445 \\
\hline & Terminal Dihexose, $\mathrm{C}_{z}$-ion & 440 & 463 \\
\hline & Internal Dihexose, $\mathrm{C} / \mathrm{Y}$-ion & 426 & 449 \\
\hline & Terminal Trihexose, $\mathbf{B}_{3}$-ion & 626 & 649 \\
\hline & Terminal Trihexose, $\mathrm{C}_{3}$-ion & 644 & 667 \\
\hline & Terminal Trihexose, $\mathrm{C}_{2 a}$-ion & 644 & 667 \\
\hline & Terminal Tetrahexose, $\mathrm{C}_{3 a-\text { ion }}$ & 848 & 871 \\
\hline & Terminal Tetrahexose, $\mathrm{C}_{4}$-ion & 848 & 871 \\
\hline & Core Man- $\beta 1,4-G \mid c N A c, B / Y / Y$ type & not applicable & 458 \\
\hline & Internal HexNAc, B/Y-ion & 245 & 268 \\
\hline & Reducing-end GlcNAc, Y-ion & 293 & not usually seen \\
\hline
\end{tabular}

with four scars. One scar would be expected from the first neutral loss in the pathway, (-293 u, GlcNAcol), while the other three must be attributed to the former mannose sites. This fixes the product ion with three hydroxyl groups, matching the sodiated mass of $\mathrm{m} / \mathrm{z}$ 648.2. Topology and linkage of this ion was supported by $\mathrm{MS}^{6}$, (Figure 2e). This spectrum provided B-ions at $\mathrm{m} / \mathrm{z} 213$ and 403 , positioning double, and single branching (two and one hydroxyl groups; e.g., scars) on the respective monomers, while the ${ }^{3,5} \mathrm{~A}_{\mathrm{n}}$-cross-ring fragments at $m / z 301.3 / 273.2,(n=2)$ and $491.2(n=3)$, identifies a sequence involving the 6- and 4-position in the core Man-GlcNAc. For each disassembly step, facile losses provide a normalized product ion spectrum with more comparable collision stability and a different metal binding and ionization cross section. These factors, coupled with the smaller number of monomers (oscillators) for energy dissipation opens the possibility of unique fragments that are most likely inaccessible by tandem MS. A measure of glycan topology (monomer connectivity) can be accessed by selecting ion pathways that rupture at critical branch junctions (central core mannose) that delineate antennae composition. These details support an isomer with $5 \mathrm{~A}_{1,2}$ topology. The familiar $\mathrm{m} / \mathrm{z} 458$ ion (Figure 2e) is used to identify core branching which represents the methylated core disaccharide fragment with three scars, $(\mathrm{HO})_{2}$ ManGlcNAc, (two hy- droxyl groups and a 1,2-ene). As seen below many of these small oligomer fragments reoccur in samples and their spectra are cautiously used as "standards" in a growing fragment library.

Three Other Structural Isomers: $\mathrm{Man}_{5} \mathrm{GlcNAc}_{2}$ $\left(5 A_{1,3} ; 5 A_{2,3} ; 5 A_{2} B_{2}\right)$

The spectral conclusions summarized for the canonical $\operatorname{Man}_{5} \operatorname{GlcNAc}_{2}\left(5 \mathrm{~A}_{1,2}\right)$ structure can be supported by following alternative disassembly pathways and product ion duplication provides assurance for specific structures (Table $2 b, c)$. But equally as noteworthy has been the observation that sequential disassembly exposes isomers when product ions are inconsistent with a presumed precursor [4]. This proved to be the case during disassembly of $5 \mathrm{~A}_{1,2}$, where the $\mathrm{MS}^{4}$ spectrum (Figure 2c) showed low abundance fragments, $\mathrm{m} / \mathrm{z}$ $445.2,533.3$ and 880.4 that could not arise from the $\left(5 \mathrm{~A}_{1,2}\right)$ canonical structure. Such fragments would be possible from a structure possessing terminal disaccharides as $B_{2}$-ions, $(\mathrm{m} / \mathrm{z} 445.2)$, and a very common corollary, an adjacent cross-ring cleavage ${ }^{3,5} \mathrm{~A}_{3}$-ions, $(\mathrm{m} / \mathrm{z}$ 533.3). Additionally, the fragment $\mathrm{m} / \mathrm{z} 880.4$ (204.2 u loss from the precursor $m / z 1084.4$, Figure 2c), with the loss of a terminal and penultimate hexose $(-218$ 


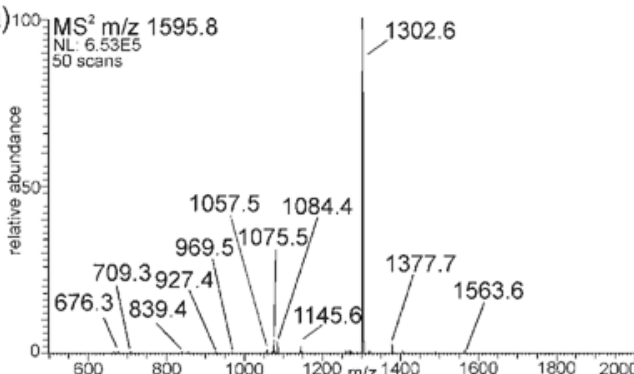

(b)

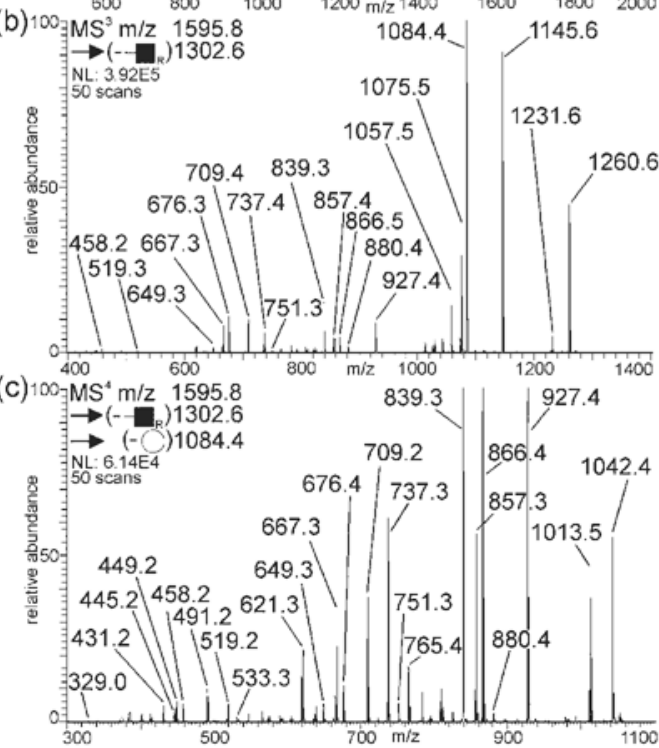

(d) 1

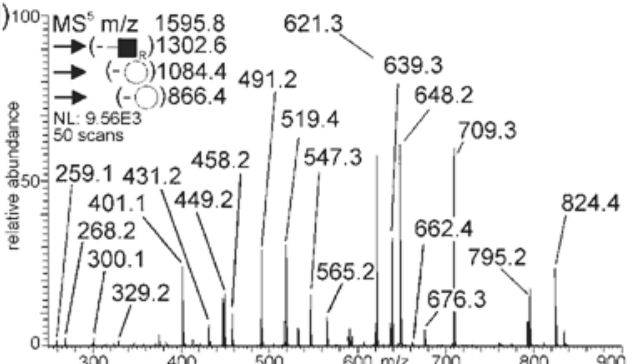

(e) $100=\mathrm{MS}^{6} \mathrm{~m} / \mathrm{z}-1595.8$

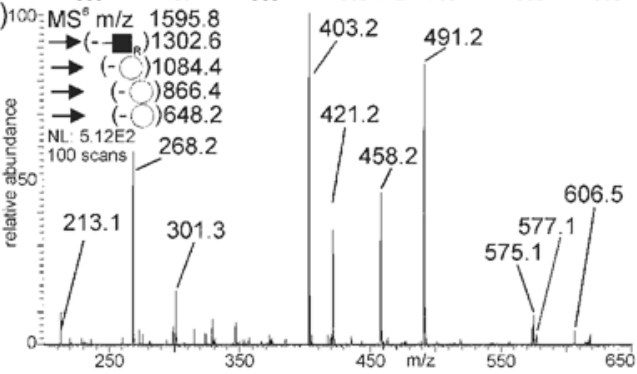

Fragmentation Assignments
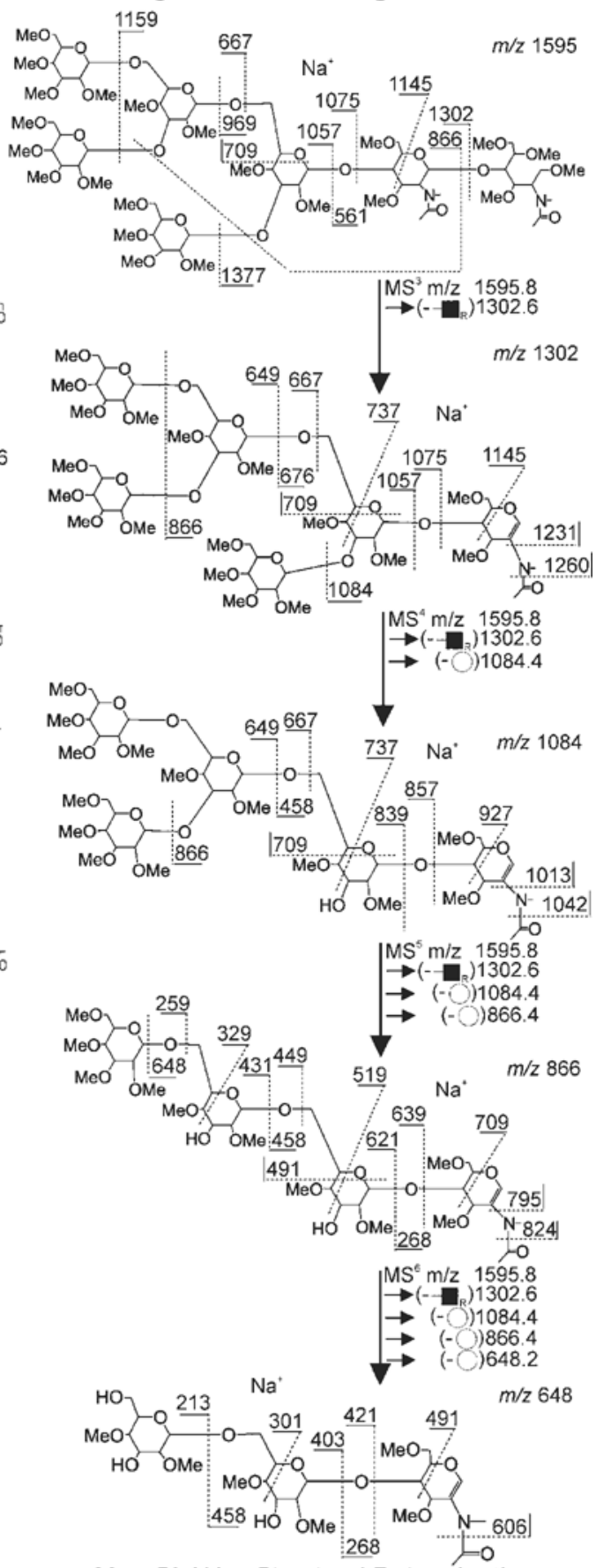

$\mathrm{Man}_{5} \mathrm{GlcNAC}_{2}$ Structural Determination:

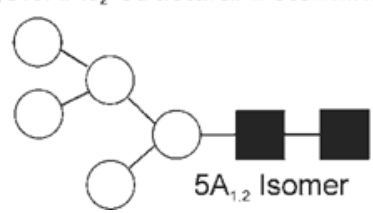

Figure 2. Sequential $\mathrm{MS}^{n}$ disassembly of the canonical $\operatorname{Man}_{5} \operatorname{GlcNAc}_{2}\left(\mathrm{~T} 1,5 \mathrm{~A}_{1,2}\right)$ isomer prepared as the methyl-reduced derivative, Man ${ }_{5}$ GlcNAcGlcNAcol. Pathways followed appear as inserts in the top left corner of the spectra (a-e). Fragments accounting for the spectrum are proposed on the structure to the right as dotted lines. The underlined fragments projecting to the right or left of the dotted line represent the sodiated ion representing that portion of the structure. 
Table 2. $\mathrm{MS}^{\mathrm{n}}$ pathways and topologies, $\mathrm{Man}_{5} \mathrm{GlcNAc}_{2}, \mathrm{~m} / \mathrm{z} 1595.8$ from RNase B.

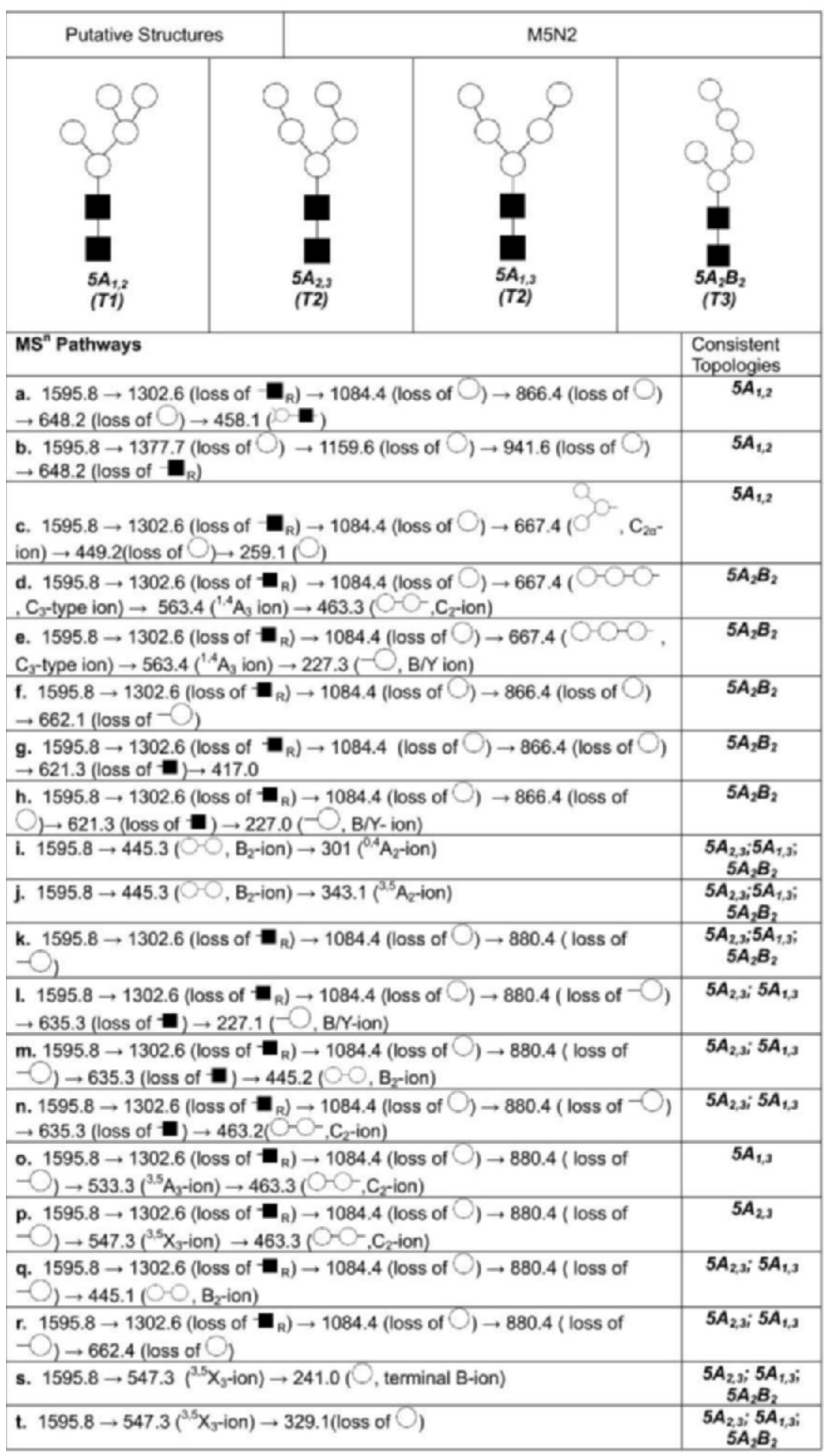

and $-204 \mathrm{u}$ ) could not be a fragment product from $5 \mathrm{~A}_{1,2}$. To evaluate this aberrant fragment $(\mathrm{m} / \mathrm{z} 880.4)$, the ion was selected and disassembled, $\mathrm{MS}^{5-7}$, (Figure $3 \mathrm{~b}-$ e), which uncovered a series of product ions indicative of T2 topology with disaccharide antennae linked from both the 3- and 6-linked mannose positions (Figure 1). A series of neutral loss products, $(m / z$ 662.2, 458.1, 268.1), were supported by the identical bond rupture but exhibiting sodium retention as B-ions, $(\mathrm{m} / \mathrm{z}$ 445.1, 635.2), (Figure 3b). This latter fragment provided a composition of $\mathrm{Man}_{3}$ with two scars which could be accounted for as GlcNAc and ${ }_{t}$ Man neutral losses yielding the respective $\mathrm{B}_{3}$ - and $\mathrm{Y}_{4}$-ions. Such fragments indicate a ${ }_{t}$ Man-Man-(HO)Man-GlcNAc se- 

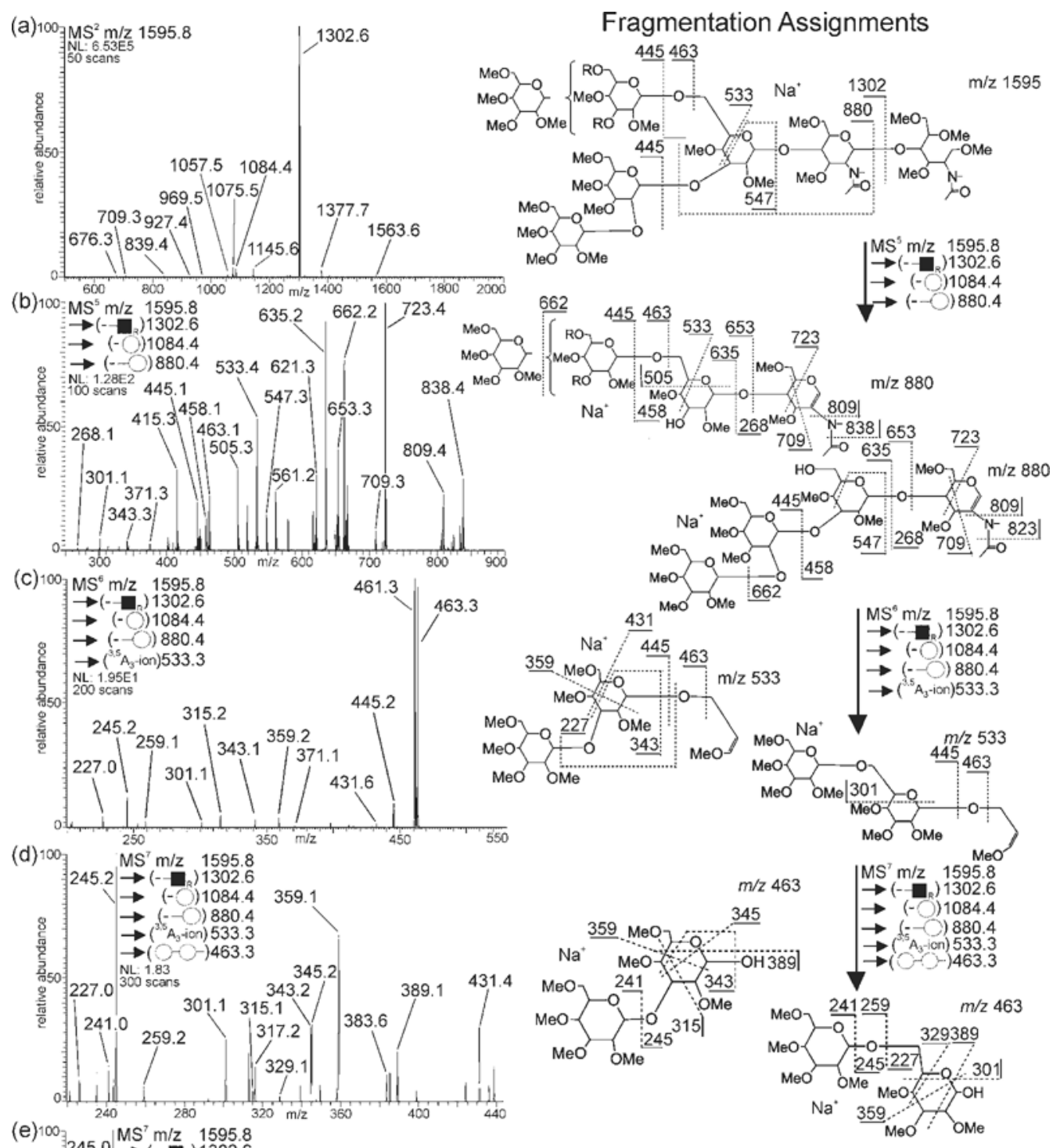

(e) $100_{3}, \mathrm{MS}^{7} \mathrm{~m} / \mathrm{z} \quad 1595.8$
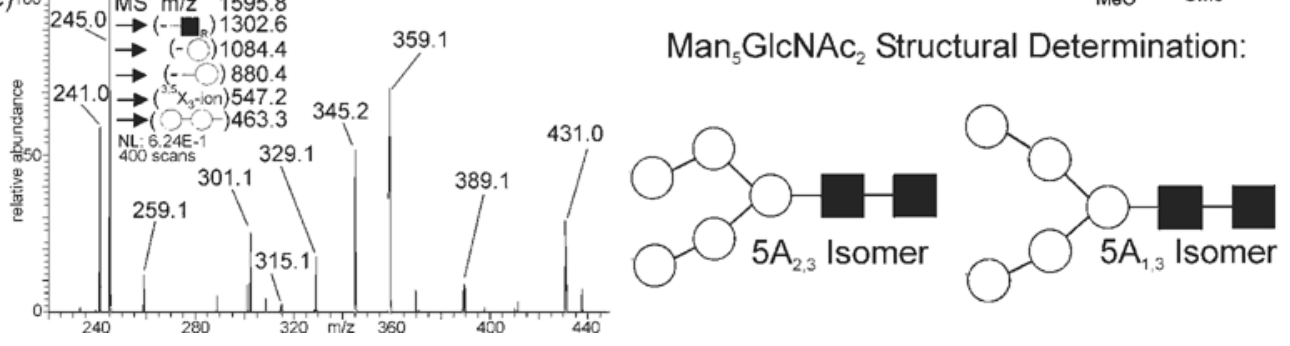

Figure 3. Sequential MS ${ }^{n}$ disassembly of the $\operatorname{Man}_{5} \mathrm{GlcNAc}_{2}\left(\mathrm{~T} 2,5 \mathrm{~A}_{1,3}\right.$ and $\left.5 \mathrm{~A}_{2,3}\right)$ isomer prepared as the methyl-reduced derivative, Man ${ }_{5}$ GlcNAcGlcNAcol. Pathways followed appear as inserts in the top left corner of the spectrum. Fragments accounting for the spectrum are proposed on the structure to the right as dotted lines.

quence. Moreover, linkage between each of the monomers was indicated with a ${ }^{4,0} \mathrm{~A}$-ion series, $(\mathrm{m} / \mathrm{z}$ 301.1, 505.3, 723.4), defining 6-, 6-, 4-interresidue linkages. The ions in this spectrum (Figure $3 b$ ) suggest a composite of three tetrasaccharide fragments and their proposed structures are presented to the right of the figure. Two of these fragments retain a 6-link as suggested by the ${ }^{0,4} \mathrm{~A}$-ion series mentioned above, Man(1-6)Man(1-4)GlcNAc, and the second would be identical with the exception of the terminal linkage, Man(1-2)Man(1-4)GlcNAc. Thus, the respective precursors must originate from structures with $\mathrm{T} 2$ topology possessing linkage isomers $5 \mathrm{~A}_{1,3}, 5 \mathrm{~A}_{2,3}$ (Figure 1). Isomer disassembly using the $m / z 880.4$ fragment filters away two other topologies (T1, T3, Table 2) and captures the core remnants of two isomeric structures, $5 \mathrm{~A}_{1,3}$, and $5 \mathrm{~A}_{2,3}$. 


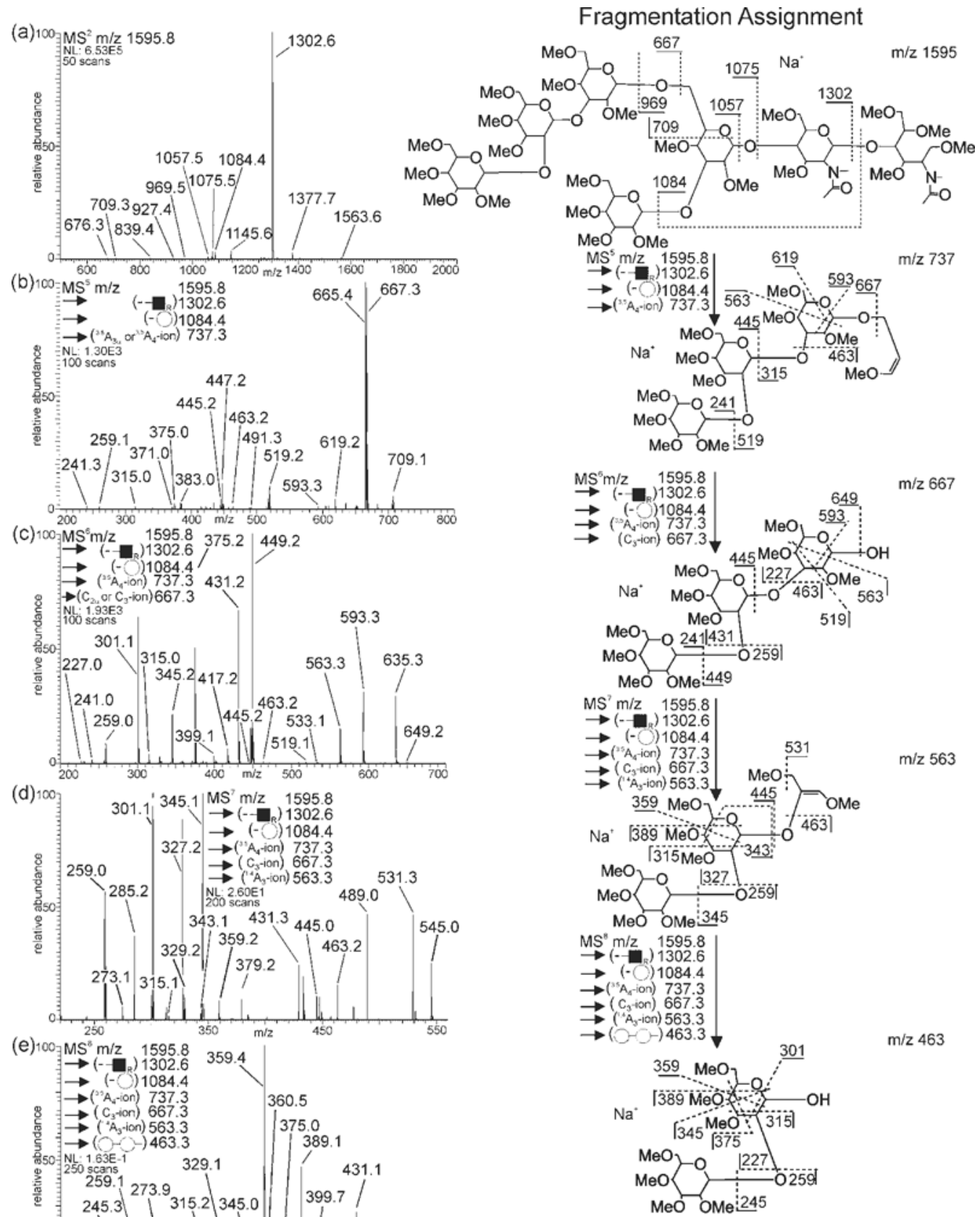

$\mathrm{Man}_{5} \mathrm{GlcNAc}_{2}$ Structural Determination:

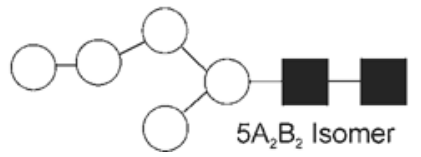

Figure 4. Sequential MS ${ }^{n}$ disassembly of the $\mathrm{Man}_{5} \mathrm{GlcNAc}_{2}\left(\mathrm{~T} 3,5 \mathrm{~A}_{2} \mathrm{~B}_{2}\right)$ isomer prepared as the methyl-reduced derivative, Man ${ }_{5} G l c N A c G l c N A c o l$. Pathways followed appear as inserts in the top left corner of the spectrum. Fragments accounting for the spectrum are proposed on the structure to the right as dotted lines.

\section{Defining Antennal Specific Topologies}

\section{$\left(\mathrm{Man}_{5} \mathrm{GlcNAc_{2 } )}\right.$}

3-Linked Antenna (T2, $5 A_{1,3} 5 A_{2,3}$ ). A disassembly pathway including the fragments $\mathrm{m} / \mathrm{z} 533.3$, and $547.2,\left({ }^{3,5} \mathrm{~A}_{3}\right.$,
$\mathrm{B}_{3^{-}}{ }^{3,5} \mathrm{X}_{3}$, respectively), provided an opportunity to study the linkage specific details of the respective 6-, and 3-linked antenna (Fig. 3d-e). The disaccharide pendant on the 3-linked core mannose was isolated with the fragment $\mathrm{m} / \mathrm{z}$ 
Table 3. $\mathrm{MS}^{\mathrm{n}}$ pathways and topologies, $\mathrm{Man}_{7} \mathrm{GlcNAc}_{2}, \mathrm{~m} / \mathrm{z} 1013.5^{2+}$ from RNase B.

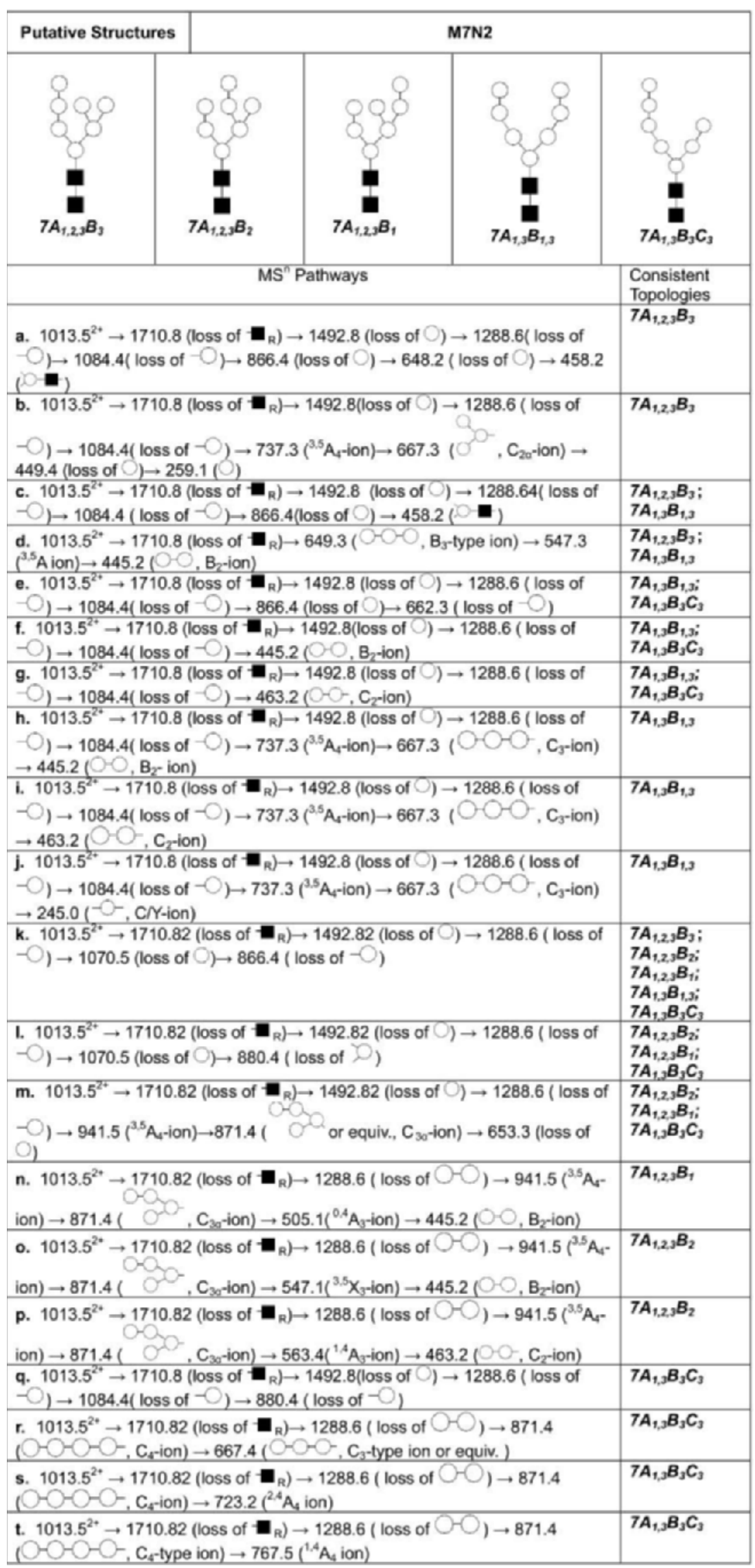


(a) 100
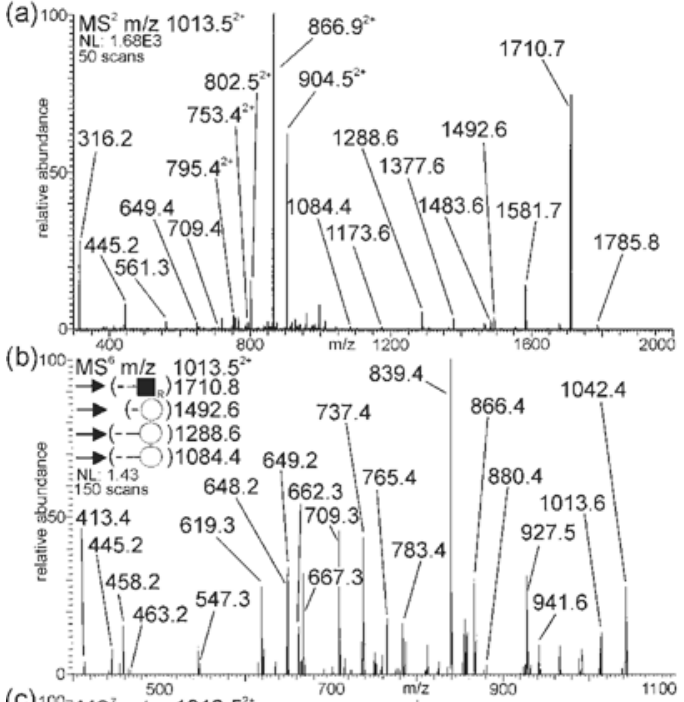

(c)
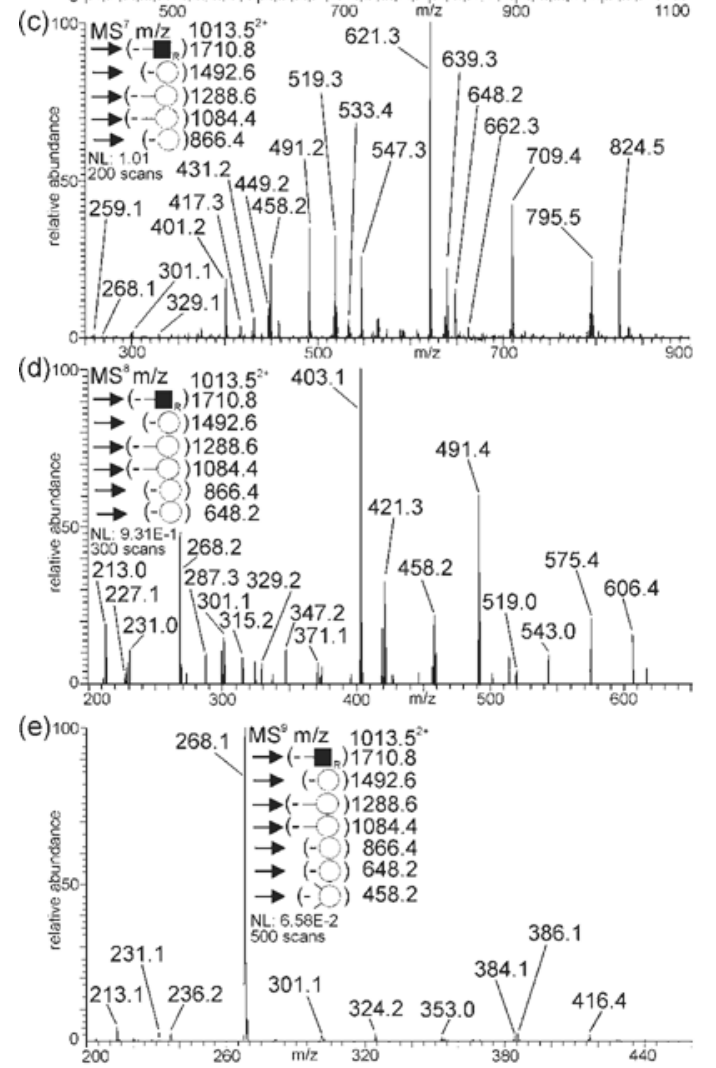
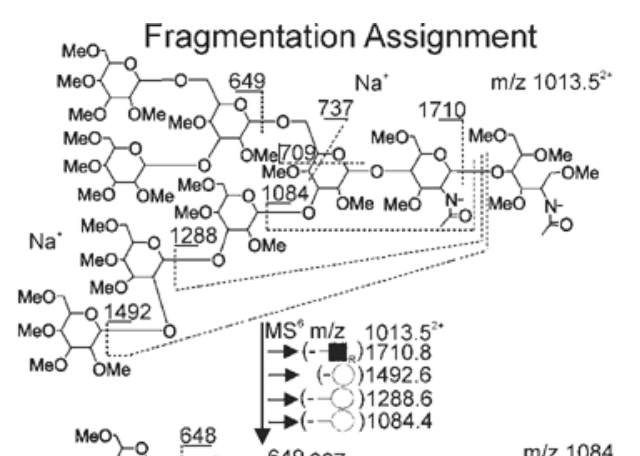

MeO OMe

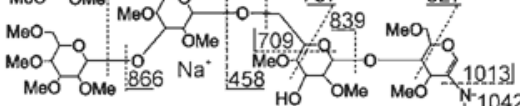

$\mathrm{MS}^{7} \mathrm{~m} / \mathrm{z} \quad 1013.5^{2 *}$

$\rightarrow\left(-D_{0}\right) 1710.8$

$\rightarrow(-\bigcirc) 1492.6$

$\rightarrow(-\infty) 1084.4$

$\mathrm{m} / \mathrm{z} 866$
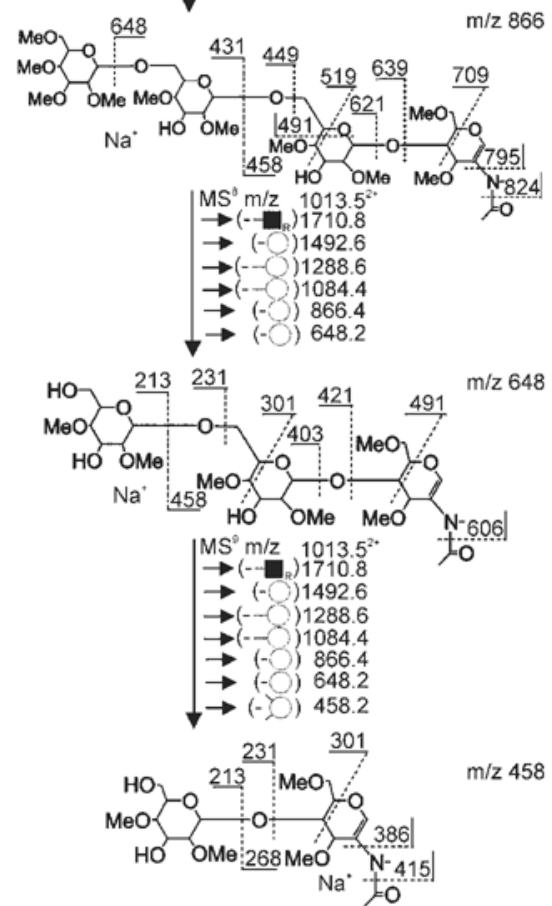

$\operatorname{Man}_{7} \mathrm{GlcNAc}_{2}$ Structural Determination:

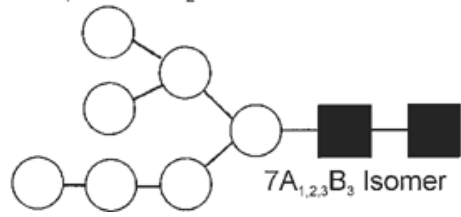

Figure 5. Sequential $\mathrm{MS}^{n}$ disassembly of the $\mathrm{Man}_{7} \mathrm{GlcNAc}_{2}\left(\mathrm{~T} 3,7 \mathrm{~A}_{1,2,3} \mathrm{~B}_{3}\right)$ isomer prepared as the methyl-reduced derivative, Man ${ }_{7}$ GlcNAcGlcNAcol. Pathways followed appear as inserts in the top left corner of each spectrum. Fragments accounting for the spectrum are proposed on the structure to the right as dotted lines.

547 (Figure 3e, pathway insert) which provided a $\mathrm{C}_{2}$-ion spectrum of the 3-linked core disaccharide $(m / z 463.3)$.

6-Linked Antenna (T2, 5 $\left.A_{1,3}, 5 A_{2,3}\right)$. The 6-linked antenna contributes two linkage isomers with $\mathrm{T} 2$ topology. They were characterized through the ion $\mathrm{m} / \mathrm{z} 533.3$ (MS $^{6}$ following the pathway (Table 2o) which provided the product spectrum (Figure $3 \mathrm{~d}$ ). The fragments indicate the spectrum to posses two disaccharide isomers, ${ }_{t} \operatorname{Man}(1-$ 6)Man-, and "Man(1-3)Man- which would be the respective 6-linked antenna core components of the isomers $5 \mathrm{~A}_{1,3}$ and $5 \mathrm{~A}_{2,3}$. On the basis of ions present, the core 


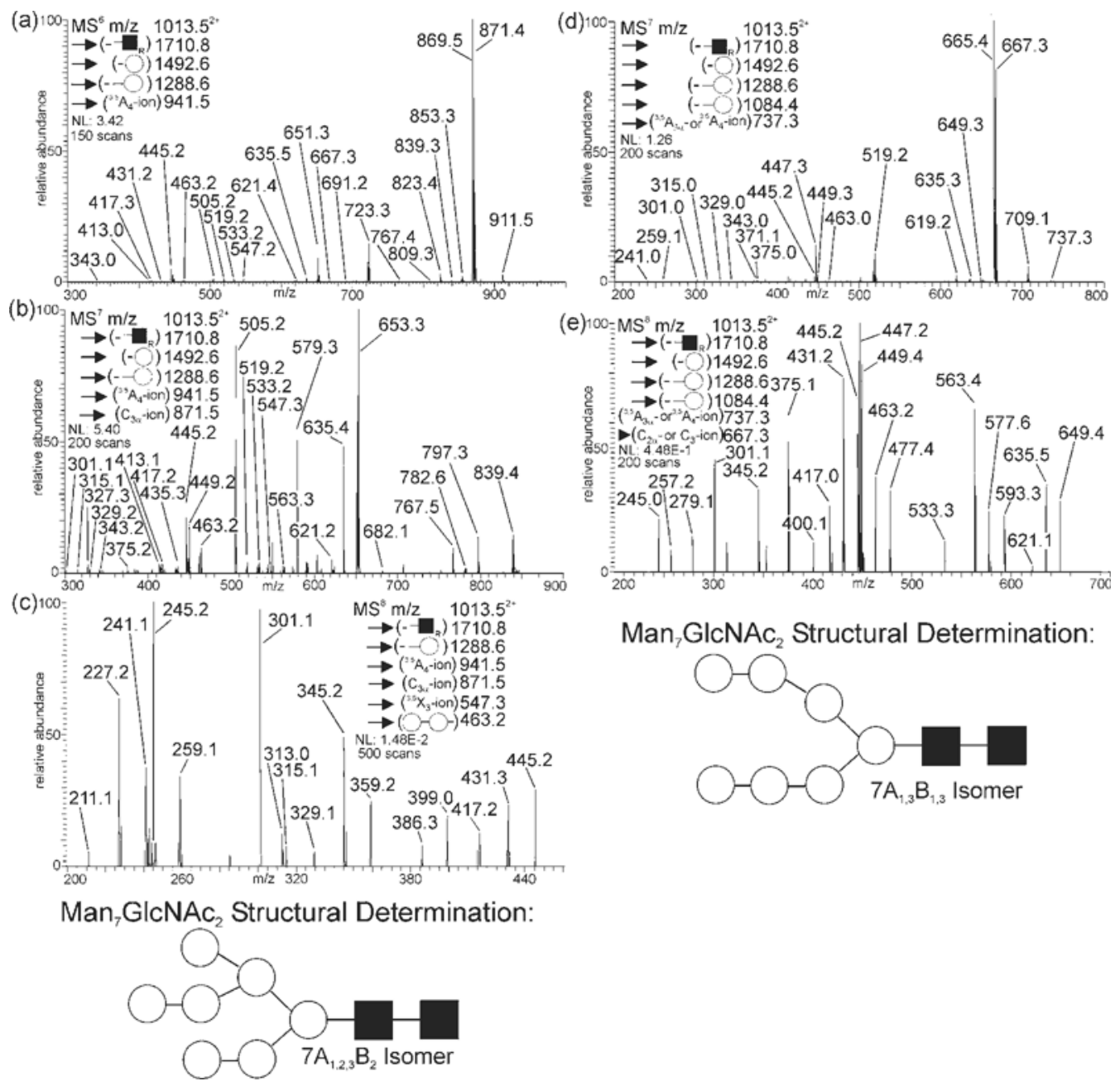

Figure 6. Sequential MS ${ }^{n}$ disassembly of isomers $\operatorname{Man}_{7} \operatorname{GlcNAc}_{2}\left(\mathrm{~T} 2,7 \mathrm{~A}_{1,2,3} \mathrm{~B}_{2}\right.$ and $\left.\mathrm{T} 2,7 \mathrm{~A}_{1,3} \mathrm{~B}_{1,3}\right)$

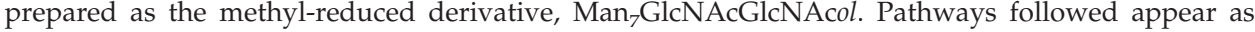
inserts in the top left corner of each spectrum. Fragments accounting for the spectrum are proposed on the structure to the right as dotted lines.

3-linked disaccharide appears to be a single ${ }_{t} \mathrm{Man}(1-$ 2)Man- structure, (Table 2p, Figure 3e). Their contrasting spectra are discussed below. Exacting confirmation could not be assured because C-ions are not in our fragment library at this time and further disassembly to B-ions could not be pursued due to a lack of signal.

6-Linked $C_{3}$-Ion Domain $\left(5 A_{2} B_{2}\right)$. In the canonical $\mathrm{Man}_{5} \mathrm{GlcNAc}_{2}$ structure an additional point of isomerism could be within the trisaccharide antenna 6-linked to the core mannose. To check this possibility the profiled ion $(m / z$ 1595.8) was isolated, fragmented in two steps to release labile residues (Figure 2c) and the 6-linked antenna was specifically isolated by selecting the ${ }^{3,5} \mathrm{~A}$-ion cross-ring cleavage of the central core mannose $\left(\mathrm{MS}^{5}, \mathrm{~m} / z\right.$ 737.3, Figure $\left.4 \mathrm{~b}\right)$. In the renormalized spectrum the $\mathrm{C}_{3}$-ion was the base ion and, as expected, retained the branched $\mathrm{C}_{2 \alpha}$-domain with characteristic ions indicating 6- and 3-linkages to a central mannose. However, there was also evidence for a linear isomer within this trisaccharide fragment with $\mathrm{B}_{2^{-}}$, and $\mathrm{C}_{2}$-ions ( $\mathrm{m} / \mathrm{z} 445.2$ and 463.2). To confirm these signals the base ion was isolated $\left(\mathrm{MS}^{6}, \mathrm{~m} / z\right.$ 667.3) and disassembled which provided a full set of abundant fragments allowing a better characterization of this precursor ion, (Figure 4c). The fragments observed in this spectrum were characteristic of $\mathrm{C}$-ions, with extensive rupture to the reducing-end monomer, $\left({ }^{0,4} \mathrm{~A}-,{ }^{1,4} \mathrm{~A}-\right.$, ${ }^{2,4} \mathrm{~A}$-ions; cf. Figure 4c). This triple set of losses, (74, 104, $148 \mathrm{u}$ ) was observed at $m / z 593.3,563.3$, and 519.1, and again following the loss of the non-reducing terminal hexose $(218 \mathrm{u})$ at $\mathrm{m} / \mathrm{z} 449.2,(\mathrm{~m} / \mathrm{z} 375.2,345.2,301.1)$. These combined losses support a linear trisaccharide and the absence of a 6-linkage, (expected for the $\mathrm{C}_{2 \alpha}$-ion from $\left.5 \mathrm{~A}_{1,2}\right)$. Such data argue for a linear $\mathrm{T} 3$ topology within the $m / z 667.3$ ion. Equally as convincing were the disaccharide fragments, $m / z 445.0$ and 463.2. With this understanding the 3-linked disaccharide was isolated $\left(\mathrm{m} / \mathrm{z}\right.$ 563.3) and disassembled $\left(\mathrm{MS}^{7}\right.$, Figure $\left.4 \mathrm{~d}\right)$ which provided access to the linkage details of this C-ion 
fragment and the isomer $5 \mathrm{~A}_{2} \mathrm{~B}_{2}, \operatorname{Man} \alpha(1-2) \mathrm{Man},\left(\mathrm{MS}^{8}\right.$, $m / z$ 463.2, Figure 4e).

The Structural Isomers of Man GlcNAc $_{2}\left(7 A_{1,2,3}\right.$ $\left.B_{1} ; 7 A_{1,2,3} B_{2} ; 7 A_{1,2,3} B_{3} ; 7 A_{1,3} B_{1,3}\right)$

To our knowledge the isomers of $\mathrm{Man}_{5} \mathrm{GlCNAc}_{2}$ have not been reported, and it was the objective of this report to contrast this non-chromatographic isomer characterization with more conventional studies of $\mathrm{Man}_{7} \mathrm{GlcNAc}_{2}$ and $\mathrm{Man}_{8} \mathrm{GlcNAc}_{2}[1-3,9]$. Using an approach identical to that described for the $\mathrm{Man}_{5} \mathrm{GlCNAc}_{2}$ glycomers, five $\mathrm{Man}_{7} \mathrm{GlcNAc}_{2}$ isomers were detected, two previously unreported. One turned out to posses a new topology (T3) within the Man ${ }_{7} \mathrm{GlcNAc}_{2}$ series $\left(\mathrm{7A}_{1,3} \mathrm{~B}_{1,3}\right.$, Figure 6, Table 3h, i), and the other $\mathrm{Glc}_{1} \mathrm{Man}_{6} \mathrm{GlNNAc}_{2}$, could be a byproduct of incomplete $\alpha$-glucosidase II Golgi processing, $\left(7 \mathrm{~A}_{1,3} \mathrm{~B}_{3} \mathrm{C}_{3}\right.$, Figure 1 and Table $\left.3 \mathrm{q}-\mathrm{t}\right)$. A similar capped 3-linked antenna was detected in the isomers of $\mathrm{Man}_{8} \mathrm{GlcNAc}_{2}$. These were assumed to be glucose residues, but this has not been confirmed. The four $\mathrm{Man}_{7} \mathrm{GlCNAc}_{2}$ isomers are represented by three topologies, two of which were identical due to branching in the 6-linked antenna, $\left(7 \mathrm{~A}_{1,2,3} \mathrm{~B}_{1}\right.$ and $\left.7 \mathrm{~A}_{1,2,3} \mathrm{~B}_{2}\right)$.

\section{Previously Identified Isomers of $\mathrm{Man}_{7} \mathrm{GlcNAc}_{2}$}

$\left(7 A_{1,2,3} B_{3} ; 7 A_{1,2,3} B_{2} ; 7 A_{1,2,3} B_{1}\right)$

The $7 A_{1,2,3} B_{3}$ Isomer (T1-Figure 5). Sequential disassembly of the methyl-reduced $\mathrm{Man}_{7} \mathrm{GlcNAc}_{2}$ precursor $(\mathrm{m} / \mathrm{z}$ $1013.5^{2+}$ ) following the pathway (Table 3a, b) identified the structure $7 A_{1,2,3} B_{3}$ (MS ${ }^{9}$, Figure 5). These results were evident from the sequential product ion compositions $(m / z 1710.7,1492.6,1288.6,1084.4)$ and their mass intervals $(-293,-218,-204,-204)$. In detail, the first ion, neutral loss of GlcNAcol, had a sodiated mass composition equal to $\mathrm{Man}_{7} \mathrm{GlcNAc}$ with one scar, the second ion, a neutral loss of a fully methylated mannose, tMan, had a sodiated mass composition equal to $\mathrm{Man}_{6} \mathrm{GlcNAc}+2$ scars. This increment in scars indicates the loss originated from a different terminus on the precursor ion. This was not the case for two subsequent losses of the third and fourth residues, $(\mathrm{m} / \mathrm{z}$ 1288.6, 1084.4, Figure 5b). This linear trisaccharide could only originate from a 3-linked antenna and signify either $7 \mathrm{~A}_{1,2,3} \mathrm{~B}_{3}$ or $7 \mathrm{~A}_{1,3} \mathrm{~B}_{1,3}$ structure (Table 1). Confirming these results were the single scarred B-ions, $m / z$ 445.2, and 649.4, (di- and trisaccharide, respectively), and the absence of any branched fragments, (doubly scarred) (Figure $5 \mathrm{~b}$ ). Resolving which of the two possible structures $\left(7 \mathrm{~A}_{1,2,3} \mathrm{~B}_{3}\right.$ or $\left.7 \mathrm{~A}_{1,3} \mathrm{~B}_{1,3}\right)$ required disassembly of the 6-linked antenna. Thus, the ${ }^{3,5} \mathrm{~A}_{4}$-ion, $(m / z$ 737.4), was isolated and disassembled following the pathway, $(\mathrm{m} / \mathrm{z}$ $667.3,449.4,259.1$, Table 3b). The first product ion and spectra supported a $\mathrm{C}_{2 \alpha}$-ion $(\mathrm{m} / \mathrm{z}$ 667.3) structure with a ${ }_{t} \mathrm{Man}$ loss and an absence of any disaccharide $\mathrm{B}_{2^{-}}$, or $\mathrm{C}_{2}$-ions. The second ion $(\mathrm{m} / \mathrm{z} 449.4)$ provided a common library spectral match with fragments supporting a
${ }_{t}$ Man $\mathrm{B}_{1^{-}}, \mathrm{C}_{1^{-}}$-ions and an ${ }^{\mathrm{O}, 4} \mathrm{~A}_{1^{-}}$fragment $(\mathrm{m} / \mathrm{z}$ 301.1) indicating a terminal mannose in a 1-6 linkage, $\operatorname{Man}(1-6)$ (HO)Man-OH. Isolation and analysis of the last ion, $\mathrm{m} / \mathrm{z}$ 259 , indicated it to be the $C_{1}$-ion of mannose. These data confirm the presence of an isomer $7 \mathrm{~A}_{1,2,3} \mathrm{~B}_{3}$. (Figure 5 , Table $3 a, b)$. Spectral identity was observed with small oligomers within the library originating from different biological sources and pathways providing reassurance of structure. Some spectra have been derived from synthetic standards; however, the majority of library files originate from well known biological sources.

The $7 A_{1,2,3} B_{2}$ Isomer (T2-Figure 6). In devising $\mathrm{MS}^{\mathrm{n}}$ pathways, an evaluation of precursor ions and their relationships provide clues of connectivity (topology). Monomer distribution between 6-, and 3-linked antenna reflected topology and these variations can be assessed in the core marker ions $\left({ }^{3,5} \mathrm{~A}_{\mathrm{n}}-,{ }^{3,5} \mathrm{X}_{\mathrm{m}}\right.$-ions, respectively, $n=4,5 ; \mathrm{m}=1,2)$. Such fragments are more apparent following neutral loss and renormalization, e.g., GlcNAcol, tMan, (cf. Figure 2a-c), and, as detailed with the previous glycomers, complexity can be resolved by including such specific ions in disassembly pathways. This provides a non-chromatographic filter that insures product-precursor relationships, and when presumed ion structures fail to match a single topology or linkage pattern this foretells isomers, (e.g., $\mathrm{Man}_{5} \mathrm{GlCNAc}_{2}$ isomers). Examples of this were the $B_{2^{-}}$, and $\mathrm{C}_{2}$-ions $(\mathrm{m} / \mathrm{z}$ 445.2, 463.2), when none would be expected (Figure 3), and the same ions in the $\mathrm{Man}_{7} \mathrm{GlcNAc}_{2}$ spectra (even after the sequential loss of the 3-linked linear trisaccharide, $m / z$ 1084.4, Figure $5 b$ ). An additional clue was the detection of a small $\mathrm{m} / \mathrm{z} 941.6$ fragment (Figure $5 \mathrm{~b}$ ), a 6-linked antenna marker fragment $204 \mathrm{u}\left({ }^{3,5} \mathrm{~A}_{\mathrm{n}}\right.$-ion, $n=$ 5) greater than that observed for the structures, $7 \mathrm{~A}_{1,2,3} \mathrm{~B}_{3}$ and $5 \mathrm{~A}_{1,2}$, indicating a tetrasaccharide at that position. But, adding a hexose monomer to the 6-linked antenna while still releasing a linear 3-linked trisaccharide summed incorrectly and could only mean the presence of two additional isomers. Isolation of this fragment $\left(\mathrm{m} / \mathrm{z}\right.$ 941.6) and collision analysis (MS ${ }^{6}$, Figure 6a) exposed a non-core marker fragment, a 3-linked trisaccharide, ${ }^{3,5} \mathrm{X}_{3}$-ion, $m / z$ 547.3, (Figure $6 \mathrm{a}$, cf. Figure $3 b$ ), and this terminal disaccharide was isolated following the pathway, $m / z$ 871.5, 547.3, 463.2 (Figure $6 \mathrm{~b}-\mathrm{c}$ ). This $\mathrm{C}_{2}$-ion, $\mathrm{m} / \mathrm{z} 463.2$, was a library match for the structure, Man(1-2)Man (Figure 6c), identifying this $\mathrm{Man}_{7} \mathrm{GlcNAc}_{2}$ isomer as $7 \mathrm{~A}_{1,2,3} \mathrm{~B}_{2}$.

The $7 A_{1,2,3} B_{1}$ Isomer (T2-Figure 7). This alternative extension of the 6-linked branch isomer (above, $7 \mathrm{~A}_{1,2,3} \mathrm{~B}_{2}$ )would have an identical topology, but a different structure as a consequence of linkage isomerism. This isomer was characterized by combining two antennae specific marker ions in the disassembly pathway, ( $m / z$ 941.5, ${ }^{3,5} \mathrm{~A}_{5}$-ion and $m / z 505.2,{ }^{\mathrm{O}, 4} \mathrm{~A}_{3}$-ion, Table $3 \mathrm{n}$ ), which would isolate the terminal upper arm disaccharide. The product of that pathway, (Figure 7a) 

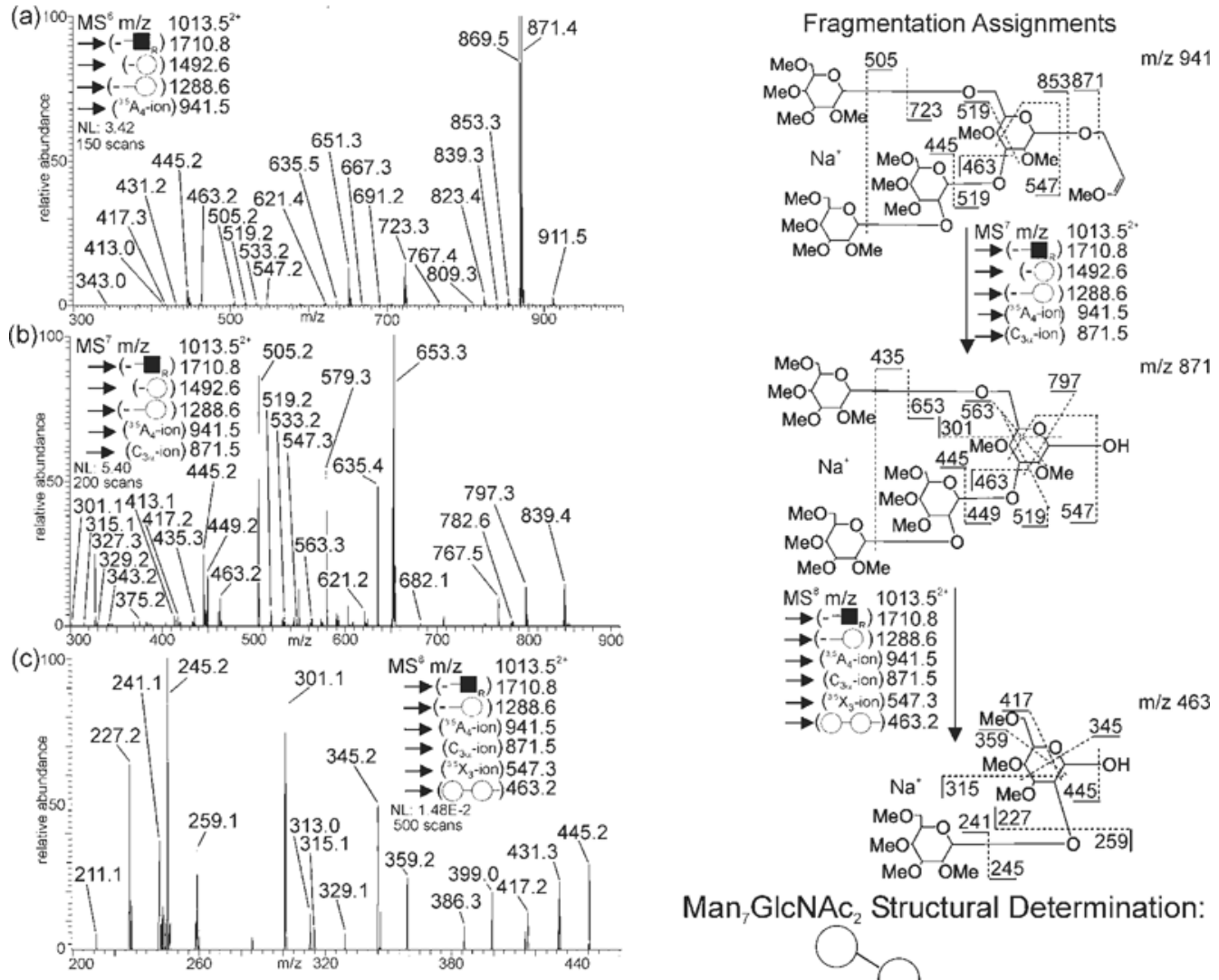

$\mathrm{Man}_{7} \mathrm{GlcNAc}_{2}$ Structural Determination:

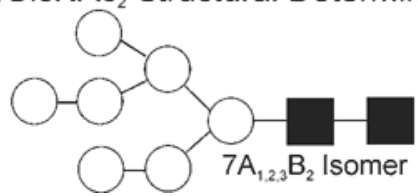

Figure 7. Sequential $\mathrm{MS}^{n}$ disassembly of isomers $\operatorname{Man}_{7} \mathrm{GlcNAc}_{2}\left(\mathrm{~T} 2,7 \mathrm{~A}_{1,2,3} \mathrm{~B}_{2}\right)$ prepared as the methyl-reduced derivative, Man ${ }_{7}$ GlcNAcGlcNAcol. Pathways followed appear as inserts in the top left corner of each spectrum. Fragments accounting for the spectrum are proposed on the structure to the right as dotted lines.

proved to be identical with the library $\mathrm{B} 2$-ion standard, Man(1-2)Man (cf. 8 $\mathrm{A}_{1,2,3} \mathrm{~B}_{1,3}$ ).

The $7 A_{1,3} B_{1,3}$ Isomer (T3, Figure 6). This unreported isomer had symmetrical topology with trisaccharide antennae extending from the mannose core at the 6- and 3-positions. This was indicated from the respective antennal marker fragments, $\left(\mathrm{m} / \mathrm{z} 737.4,{ }^{3,5} \mathrm{~A}_{4}\right.$-ion, and $\mathrm{B}_{n^{-}},{ }^{3,5} \mathrm{X}_{3^{-}}$ ion, $m / z$ 751.4). The topology was homologous with the $5 \mathrm{~A}_{1,3}$ isomer differing by one monomer $(204 \mathrm{u})$ on each antenna, (Figure $3 b$ ). Confirmation was pursued by isolating each marker fragment and disassembling the respective antennae (Figure $6 \mathrm{~d}$, Table $3 \mathrm{~h}, \mathrm{i}$ ). Analysis of the 6-linked antenna, $(\mathrm{m} / \mathrm{z} 737.4)$ provided a spectrum identical with the same mass from isomer $5 \mathrm{~A}_{2} \mathrm{~B}_{2}$, (cf. MS , Figure $4 \mathrm{~b}$ and $\mathrm{MS}^{7}$, Figure $6 \mathrm{~d}$ ). Further analysis of this C-ion trisaccharide by selecting the base ion $(\mathrm{m} / \mathrm{z}$ 667.3) for disassembly, however, provided a significantly different spectrum (Figure 6e) than the comparable ion product, (Figure 4c). This difference must be a reflection of the structure, Man(1-2)Man(1-6)Man (Figure 6e) in contrast to the isomer Man(1-2)Man(1-3)Man (Figure 4c). Further characterization of this trisaccharide product (Table 3g-i) showed the disaccharide non-reducing terminus $(\mathrm{m} / \mathrm{z}$ 463.2) to be identical. These products define the isomer to be $7 \mathrm{~A}_{1,3} \mathrm{~B}_{1,3}$.

The Structural Isomers of $\mathrm{Man}_{8} \mathrm{GlcNAc}_{2}$ $\left(8 A_{1,2,3} B_{1,2} ; 8 A_{1,2,3} B_{1,3} ; 8 A_{1,2,3} B_{2,3}\right)$

Three $\mathrm{Man}_{8} \mathrm{GlcNAc}_{2}$ isomers have been reported [1, 3-6], and these structures differ from a $\mathrm{Man}_{9} \mathrm{GlcNAc}_{2}$ glycomer by having one missing $\alpha$-2mannose residue on the termini of each antenna (Figure 1). Since several antennae have been previously characterized in this report, the detailing of subsequent structures for the Man8 isomers would be a matter of revisiting those ions. The basic approach was to expose topology through the core mannose marker ions followed by probing the linkage details in the selected domains. However, the $8 \mathrm{~A}_{1,2,3} \mathrm{~B}_{1,2}$ isomer could not be approached in this manner, because of the greater lability of the mannose termini which exceeded that of the $[3,5] \mathrm{A}_{6}$ marker ion. This required an alternative marker ion. 

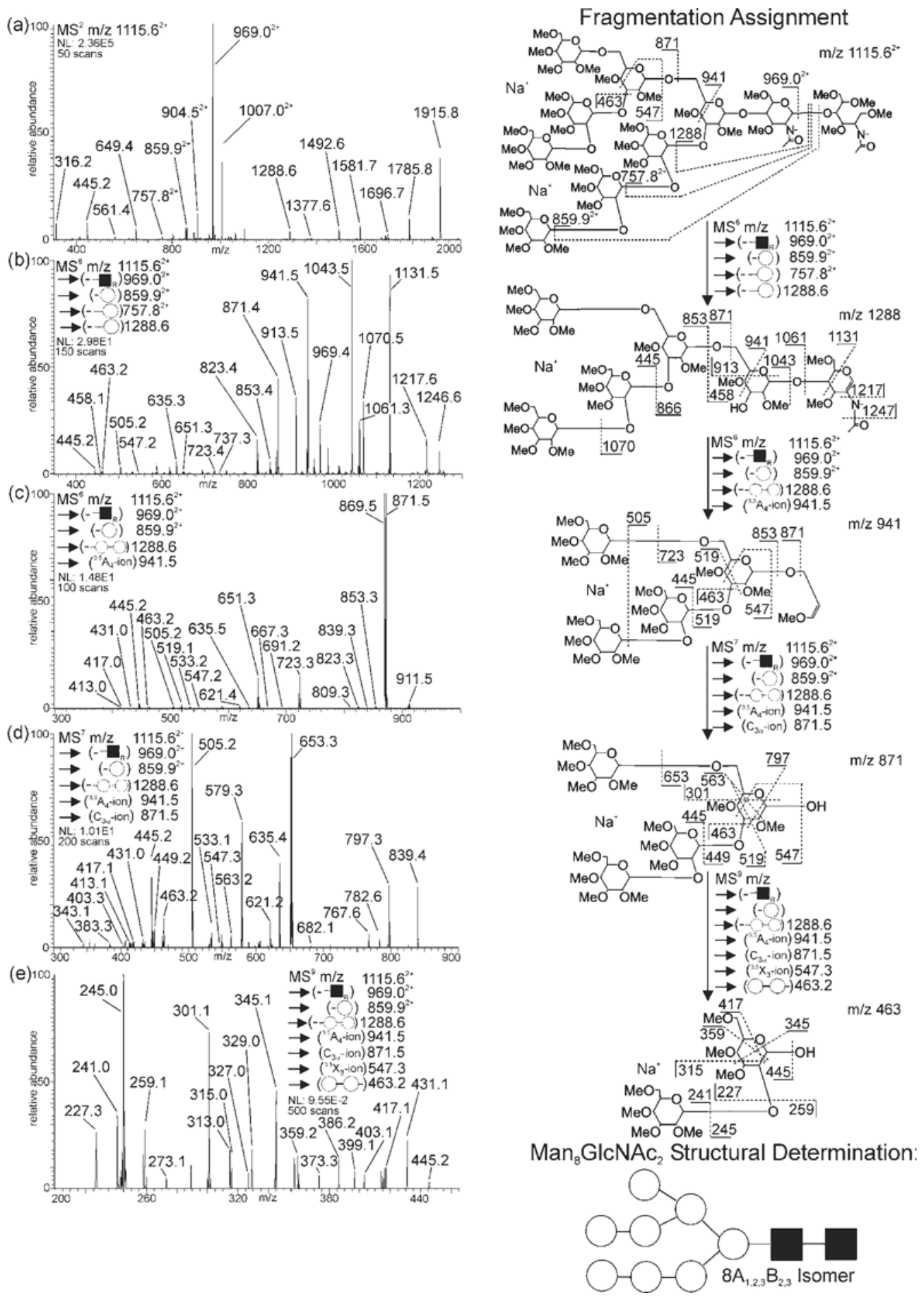

Figure 8. Sequential MS ${ }^{n}$ disassembly of isomers $\mathrm{Man}_{7} \mathrm{GlCNAc}_{2}\left(\mathrm{~T} 2,7 \mathrm{~A}_{1,2,3} \mathrm{~B}_{2,3}\right)$ prepared as the methyl-reduced derivative, $\mathrm{Man}_{8}$ GlcNAcGlcNAcol. Pathways followed appear as inserts in the top left corner of each spectrum. Fragments accounting for the spectrum are proposed on the structure to the right as dotted lines.

$\operatorname{Man}_{8} G N A c_{2}\left(T 1,8 A_{1,2,3} B_{1,3}\right)$. As with the Man ${ }_{7}$ glycomers, branching within the 6-linked antenna introduced a pair of isomeric structures that comprised one topological grouping, $\left(\mathrm{T} 1,8 \mathrm{~A}_{1,2,3} \mathrm{~B}_{1,3} ; 8 \mathrm{~A}_{1,2,3} \mathrm{~B}_{2,3}\right)$, and the second topology was represented by a single structure with a shortened 3-linked antenna, $\left(\mathrm{T} 2,8 \mathrm{~A}_{1,2,3} \mathrm{~B}_{1,2}\right)$. No additional topologies could be envisioned within the footprint of the $\mathrm{Man}_{8}$ processed glycomers. Thus, the structural isomers of $\mathrm{Man}_{8}$ were approached in the usual manner by releasing the terminal GlcNAcol, a 3-linked linear antenna, and renormalizing the product spectra, (Figure 7 and Figure $8 \mathrm{a}-\mathrm{d}$, Table 4e). The linear trisaccharide loss while main- 
Table 4. $\mathrm{MS}^{\mathrm{n}}$ pathways and topologies, $\mathrm{Man}_{8} \mathrm{GlcNAc}_{2}, \mathrm{~m} / \mathrm{z} 1115.6^{2+}$ from RNase B.

\begin{tabular}{|c|c|c|}
\hline Putative Structures & \multicolumn{2}{|l|}{ M8N2 } \\
\hline & $8 A_{1,2,3} B_{1,2}$ & ${ }_{1,2,3} B_{1,2} C_{3}$ \\
\hline \multicolumn{2}{|l|}{ MS"Pathways } & $\begin{array}{l}\text { Consistent } \\
\text { Topologies }\end{array}$ \\
\hline \multicolumn{2}{|c|}{ 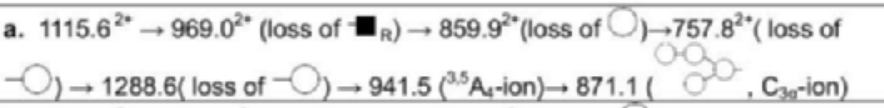 } & $\begin{array}{c}\mathbf{8} A_{1,2,3} B_{2,3} \\
8 A_{1,2,3} B_{1,3}\end{array}$ \\
\hline \multicolumn{2}{|c|}{ 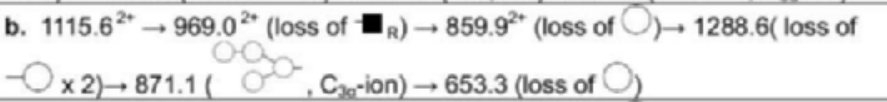 } & $\begin{array}{l}8 A_{1,2,2} B_{2,3 ;} \\
8 A_{1,2,3} B_{1,3}\end{array}$ \\
\hline \multicolumn{2}{|c|}{ 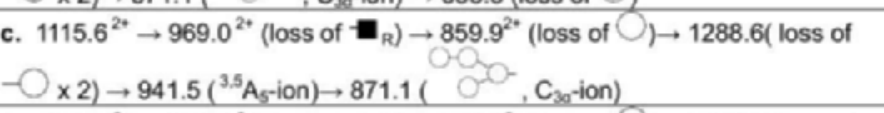 } & $\begin{array}{l}8 A_{1,2,3} B_{2,3 ;} \\
8 A_{1,2,3} B_{1,3}\end{array}$ \\
\hline \multicolumn{2}{|c|}{ 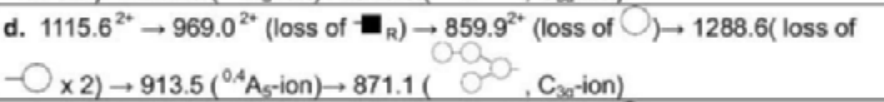 } & $\begin{array}{c}8 A_{1,2,3} B_{2,3} \\
8 A_{1,2,3} B_{1,3}\end{array}$ \\
\hline \multicolumn{2}{|c|}{ 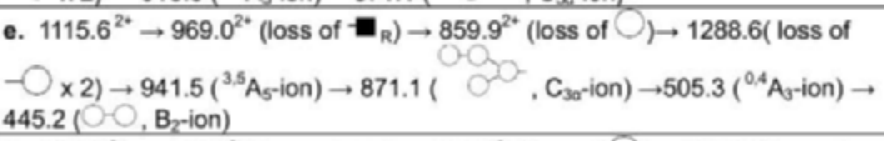 } & $8 A_{1,2,3} B_{1,3}$ \\
\hline \multicolumn{2}{|c|}{ 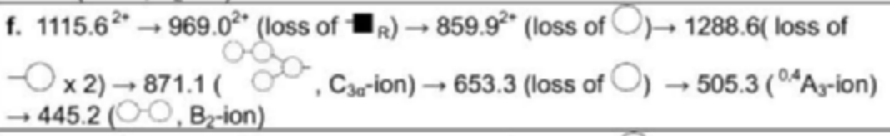 } & $8 A_{1,2,3} B_{1,3}$ \\
\hline \multicolumn{2}{|c|}{ 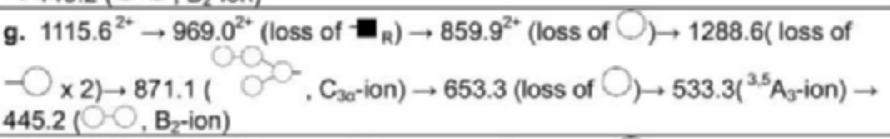 } & $\begin{array}{c}8 A_{1,2,3} B_{2,3 i} \\
8 A_{1,2,3} B_{1,3}\end{array}$ \\
\hline \multicolumn{2}{|c|}{ 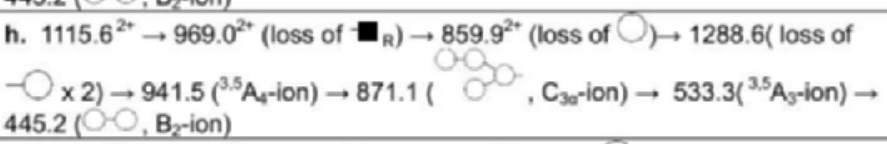 } & $\begin{array}{l}8 A_{1,2,3} B_{2,3} \\
8 A_{1,2,3} B_{1,3}\end{array}$ \\
\hline \multicolumn{2}{|c|}{ 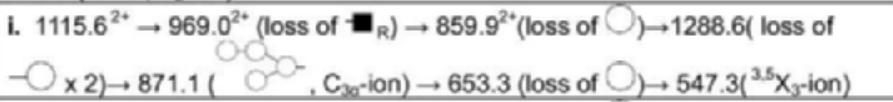 } & $8 A_{1,2,3} B_{2,3}$ \\
\hline \multicolumn{2}{|c|}{ 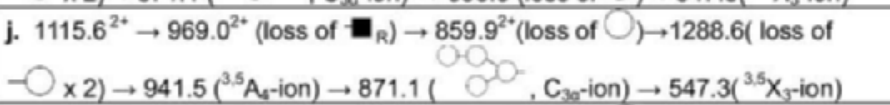 } & $8 A_{1,2,3} B_{2,3}$ \\
\hline \multicolumn{2}{|c|}{ 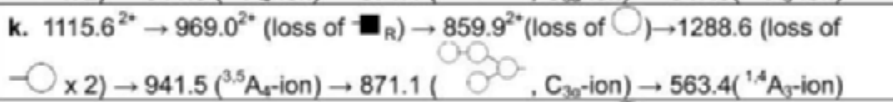 } & $8 A_{1,2,3} B_{2,3}$ \\
\hline \multicolumn{2}{|c|}{$\begin{array}{l}\left.\left.\text { I. } 1115.6^{2+} \rightarrow 969.0^{2+} \text { (loss of } \mathbf{n}_{R}\right) \rightarrow 859.9^{2+} \text { (loss of }\right) \rightarrow 1288.6 \text { (loss of } \\
-(x) \rightarrow 871.1\left(-C_{4} \text {-ion }\right) \rightarrow 667.3(\text { loss of }-O \text { ) }\end{array}$} & $8 A_{1,2,3} B_{1,2} C_{3}$ \\
\hline \multicolumn{2}{|c|}{ 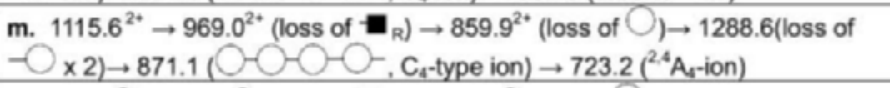 } & $8 A_{1,2,3} B_{1,2} C_{3}$ \\
\hline \multicolumn{2}{|c|}{ 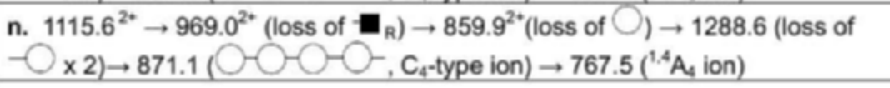 } & $8 A_{1,2,3} B_{1,2} C_{3}$ \\
\hline \multicolumn{2}{|c|}{$\begin{array}{l}\text { o. } 1115.6^{2+} \rightarrow 969.0^{2+}\left(\text { loss of } \mathbf{U}_{R}\right) \rightarrow 859.9^{2+}(\text { loss of } \bigcirc) \rightarrow 757.8^{2+}(\text { loss of } \\
\left.-O_{1} \rightarrow 1274.5 \text { (loss of } \bigcirc\right) \rightarrow 1070.5(\text { loss of }-() \rightarrow 880.4 \text { (loss of } D \text { ) }\end{array}$} & $8 A_{1,2,3} B_{1,2}$ \\
\hline \multicolumn{2}{|c|}{ 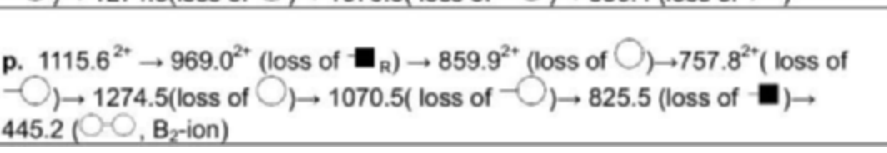 } & $8 A_{1,2,3} B_{1,2}$ \\
\hline
\end{tabular}


taining the ${ }^{3,5} \mathrm{~A}_{5}$-ion composition $(\mathrm{m} / \mathrm{z}$ 941.5) confirmed the T1 topology and the location of the isomeric linkages. These product spectra were analogous to the isomer $7 \mathrm{~A}_{1,2,3} \mathrm{~B}_{1}$, (cf. Figure $6 \mathrm{a}, \mathrm{b}$ and Figure 7 , respectively), and this spectral identity characterized the $\mathrm{Man}_{8}$ isomer as $8 \mathrm{~A}_{1,2,3} \mathrm{~B}_{1,3}$ with a matching B-ion product, Man(1-2)Man, $\left(\mathrm{MS}^{9}, \mathrm{~m} / \mathrm{z}\right.$ 445.2).

$\operatorname{Man}_{8} \operatorname{GNAc}_{2}\left(T 1,8 A_{1,2,3} B_{2,3}\right)$. The isomeric structure in the 6-linked domain representing the isomer $8 \mathrm{~A}_{1,2,3} \mathrm{~B}_{2,3}$ was approached in a similar manner using the ${ }^{3,5} \mathrm{~A}_{n}$ pathway fragment $m / z$ 941.5. But identical to the $\mathrm{Man}_{7}$ isomer $\left(7 \mathrm{~A}_{1,2,3} \mathrm{~B}_{2}\right)$ a second marker ion, ${ }^{3,5} \mathrm{X}_{3}, \mathrm{~m} / \mathrm{z} 547.3$ was included in the pathway (Table $4 \mathrm{i}, \mathrm{j}$ ) to isolate the 3-linked disaccharide structure. The spectral identity at this position for the $\mathrm{C}_{2}$-ion Man(1-2)Man confirmed the $8 \mathrm{~A}_{1,2,3} \mathrm{~B}_{2,3}$ isomer, (Figure 8).

$\operatorname{Man}_{8} \operatorname{GNAc}_{2}\left(T 2,8 A_{1,2,3} B_{1,2}\right)$. This last isomer proved to be quite different in its activation stability, and alternative fragment ions had to be considered to define the structural details. In the previous glycomers we had relied on the marker ions ${ }^{3,5} \mathrm{~A}_{n}$ and ${ }^{3,5} \mathrm{X}_{n}$-ions to sort topology in the 6- and 3-linked antenna. These fragments and their correlated mass shifts help identify markers, but when neutral loss fragments dominate the spectra this identity is lost. Thus, an alternative approach is to search for fragments that would expose elements of structure in a product spectrum. Trimming labile GlcNAcol, a disaccharide, and tMan residues provided a series of $\mathrm{B}$-ions that defined a backbone sequence that could only be understood as an $8 \mathrm{~A}_{1,2,3} \mathrm{~B}_{1,2}$ isomer (Figure 9, Table 4o, p). Particularly defining were the ion series $\mathrm{m} / \mathrm{z}$ 505.3; 695.3; 913.4; indicating a sequence ${ }_{t} \operatorname{Man}-\operatorname{Man}(1-6)(\mathrm{HO}) \operatorname{Man}(1-6)(\mathrm{HO}) \operatorname{Man}(1-4)$ GlcNAc ( $m / z$ 1070.5, Fig. c), and its precursor ion, with an incrementing terminal disaccharide, (Figure 9b, $\mathrm{m} / \mathrm{z}$ 1274.5). The only isomer that would fit these fragments would be $8 \mathrm{~A}_{1,2,3} \mathrm{~B}_{1,2}$.

As mentioned above for the $\mathrm{Man}_{7} \mathrm{GlcNAc}_{2}$ isomers, a glucose capped, 3-linked linear tetrasaccharide $\left(\mathrm{Hex}_{1} \mathrm{Man}_{6} \mathrm{GlcNAc}_{2}\right)$ was also detected in the isomers of $\operatorname{Man}_{8} \mathrm{GlcNAc}_{2},\left(8 \mathrm{~A}_{1,3} \mathrm{~B}_{1,3} \mathrm{C}_{3}\right.$, Figure 1 and pathways Table 4 l-nm). The stereochemistry of this glucose residue was not specifically determined and only assigned on the basis of a 3-linked linear tetrasaccharide antenna versus trisaccharide in the high-mannose footprint. This was coupled with the requisite ${ }^{3,5} \mathrm{~A}_{n}$-marker ions, where $n=3$ for $\mathrm{Man}_{7},(m / z$ 533.6), and $n=4$ for $\mathrm{Man}_{8}(\mathrm{~m} / \mathrm{z}$ 941.5). For both structures, the sequential loss of a ${ }_{t}$ Man with a product composition of one scar, followed by three $204 \mathrm{u}$ losses, with no increment in scars, provided the information for concluding glucose capping.

\section{Discussion}

Protocols to understand carbohydrate structure include a large list of mass spectral instruments coupled with

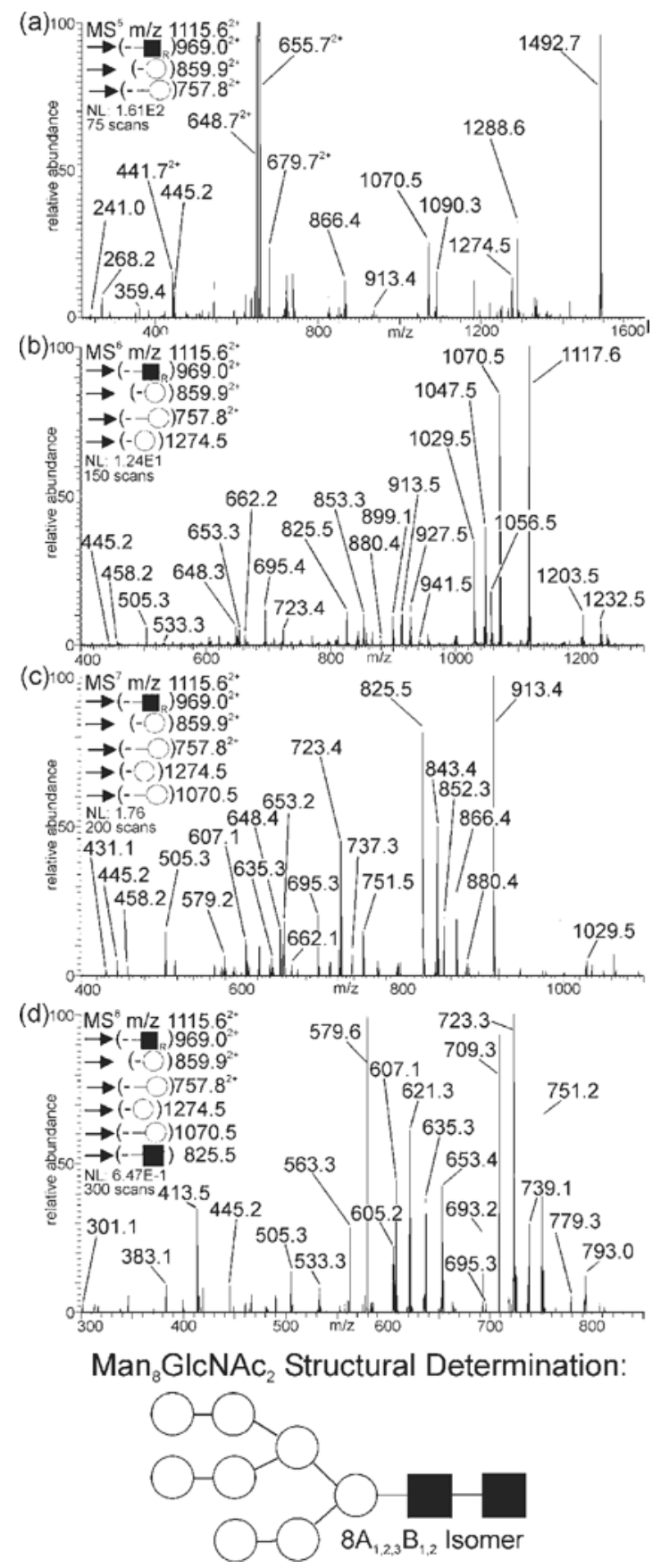

Figure 9. Sequential MS ${ }^{n}$ disassembly of isomers $\mathrm{Man}_{7} \mathrm{GlcNAc}_{2}$ (T2, $7 \mathrm{~A}_{1,2,3} \mathrm{~B}_{1,2}$ ) prepared as the methyl-reduced derivative, $\mathrm{Man}_{8} \mathrm{Gll}_{\mathrm{C} A c G l c N A c o l}$. Pathways followed appear as inserts in the top left corner of each spectrum. Fragments accounting for the spectrum are proposed on the structure to the right as dotted lines.

numerous ionization techniques, and interfaced with various chromatographic methods. These provide improved component and mass resolution with differing strategies to induce fragmentation. Although some glycan structures may be better understood with improved mass accuracy, the transparency of linkage, branching, and stereochemical features brings new challenges beyond ion mass resolution. Combinations of internal and 
external source fragmentation techniques are striking and represent the cutting-edge of fixed energy deposition, and it may be too early to comment on the advantages such strategies bring to glycan analysis. But, as the energy of excitation becomes more selective the general features of activation of all linkage types may be missed.

In this report we have discussed how ion trap mass spectrometry can couple precursor isolation with sequential disassembly to define glycan topology and expose isomers in a non-chromatographic understanding of structure. This ion control is a salient feature for carbohydrate sequencing that allows a focus on glycan domains (antenna) and subsequently to specific interresidue linkages. Disassembly with the ion trap also carries a different and variable set of physical parameters to induce fragmentation, and this takes place with each precursor-product step. Another aspect that plays most importantly into stepwise disassembly is the decreasing number of oscillators for energy dissipation thereby providing effective energy resolution [12]. Thus, structural details inherent to understanding linkages are maximally displayed in disaccharides, (cf. Figure $4 \mathrm{a}$ and e). These attributes have been delineated in this study with RNase B glycans, a paradigm sample used by many. In repeating this application, it is hoped that the more comprehensive data presented here would provide greater insight into the subtleties and value of the ion trap as a carbohydrate sequenator. For the $\mathrm{Man}_{5} \mathrm{GlCNAc}_{2}$ glycomer three topologies that include four linkage isomers are detailed, three of which appear to be unreported. Selected ions indicative of isomeric structures have been listed in $\mathrm{MS}^{2}$ spectra of $\mathrm{Man}_{5} \mathrm{GlcNAc}_{2}$ where they were apparently assigned incorrectly [2], and even partially resolved in an extracted ion chromatogram, although such heterogeneity was not discussed [1]. The three previously characterized isomers of $\mathrm{Man}_{7}$ and $\mathrm{Man}_{8}$ have been also identified plus one additional unreported $\mathrm{Man}_{7}$ isomer. Two additional products have been recognized that suggest incomplete $\alpha$-glucosidase activity in the processing pathway of the $\mathrm{Man}_{7}$ and $\mathrm{Man}_{8}$ glycoproteome structures. All isomers have been identified with a single instrument type without any ancillary techniques of ionization, chromatographic interfacing, or ion activation. The lack of detecting sensitivity must account for the inability of NMR to identify these low abundance isomers [9], esp., the $\mathrm{Man}_{5} \mathrm{GlcNAc}_{2}$ structures, while in contrast, nanospray static infusion (TriVersa NanoMate) and signal averaging for extended periods exposes unique opportunities to detect trace sample amounts.

In describing the specific spectra, the stereochemistry of monomers were assumed on the basis of their susceptibility to endoglycosidase release, molecular weights, and position in the high mannose motif, $\mathrm{Man}_{9} \mathrm{GlcNAc}_{2}$. Where the 3-linked antennae were capped with an additional hexose, it was understood to be glucose and a product of incomplete $\alpha$-glucosidase II activity. No confirmation by GLC-MS was performed. For the $\mathrm{Man}_{5} \mathrm{GlcNAc}_{2}$ glycomer of RNase B, four linkage isomers have been detected which fall into three unique branching topologies. This word topology has been adapted from the field of mathematics and applied to delineate glycan connectivity and separate from identification of linkage isomers. For the glycomers of $\mathrm{Man}_{7} \mathrm{GlcNAc}_{2}$ and $\mathrm{Man}_{8} \mathrm{GlCNAc}_{2}$ the three linkage isomers all have a unique topology. The abundance of individual isomers within the $\mathrm{Man}_{7}$ and $\mathrm{Man}_{8}$ glycomers has been summarized and reported [1, 9, 10]. Providing such information on the basis of fragment abundance would require information not available and was not considered. The ability to identify minor components in a field dominated by other isomeric structures has important implications for the detection and tracking of altered cellular processes. The trace levels initiating function, coupled with the dynamic and temporal aspects of glycosylation will be the bona fide structural challenge when contrasted to the tissue glycome. Under these circumstances, we anticipate ITMS instrumentation to be alone in approaching such problems.

A comprehensive evaluation of a sample glycome must entail checking for all possible isomers and a low mass scanning range that includes disaccharides, where unique structural details could exist. Rarely are glycoproteome glycans single structures, but appear to represent a distribution of multiple topologies and isomers. This would strongly suggest that tandem MS alone to be quite inappropriate for providing a comprehensive structural evaluation. As one of many examples, the $\mathrm{MS}^{2} \mathrm{C}_{2 \alpha}$ fragment of $\mathrm{Man}_{5} \mathrm{GlcNAc}_{2}, \mathrm{~m} / \mathrm{z}$ 667.3 (Figure 2a) was shown to exist as a linear trisaccharide, T3 (Figure 4). Although low in abundance, such fragments are well within the dynamic range necessary for further evaluation, and when free from more facile ruptures are renormalized for subsequent $\mathrm{MS}^{n}$ steps, (cf. Figure 3a and $3 b$ ). Directing disassembly along pathways that include 6- and 3-linked antennal fragments also insures specificity, and this was the strategy and pathway that provided the two isomers within the $\mathrm{C}_{2 x}$-ion 3-linked antennal domain of the putative $\mathrm{Man}_{5} \mathrm{GlcNAc}_{2}$ structure (Figure $3 a-e)$. These spectra show prominent $B_{2}$ and $C_{2}$ fragments and the expected 6-linked, ${ }^{4, O} A_{2}, m / z$ 301.1, and ${ }^{3,4} X_{2}, m / z 375.2$, and 3-linked ${ }^{2,4} A_{2}, m / z 315.0$ fragments consistent with the branched Man1-6(Man13)Man topology. But importantly, the fragments, $\mathrm{m} / \mathrm{z}$ 227.0, 463.2, 519.1, 533.1 and 563.3, $\left(\mathrm{Y}_{2}, \mathrm{C}_{2}{ }^{2,4} \mathrm{~A}_{3},{ }^{3,5} \mathrm{~A}_{3}\right.$, and ${ }^{1,4} \mathrm{~A}_{3}$, respectively), are separately and collectively indicating a linear $C_{3}$ fragment topology (Figure 3a). The fragment $m / z 563.3$ specifies the linear extension is at the 3-position and isolation of that ion, $\mathrm{MS}^{6}$, provided a spectrum exhibiting glycosidic cleavage at $\mathrm{m} / \mathrm{z} 259.0$, 327.2, 345.1, 445.0, and $463.2\left(\mathrm{C}_{1}, \mathrm{Z}_{2}, \mathrm{Y}_{2}, \mathrm{~B}_{2}\right.$, and $\mathrm{C}_{2}$, respectively), (Figure $3 \mathrm{~b}$ ). To focus specifically on the terminal linkage within this 3-linked antenna, the $\mathrm{C}_{2}$ fragment, $m / z$ 463.2, was isolated which provided the $\mathrm{MS}^{7}$ spectrum (Figure $3 \mathrm{c}$ ). Here again, as in the terminal 
disaccharide fragments of the D2 topology, linkage multiplicity reigns. Fragment ions $m / z$ 227.0, 245.2, and $259.1\left(Z_{1}, Y\right.$, and $C_{1}$, respectively), define the glycosidic ruptures, while the cross-ring fragments for the 3-, and 6-linkage can be easily observed, ( $\mathrm{m} / \mathrm{z}$ 315.1, 389.1, 329.1, 301.1). This provides detailed evidence of linkage isomers at that position with $\mathrm{Man}_{5} \mathrm{GlcNAc}_{2}$, in the T3 topology (Figure 1 and Figure 3).

This diversity of RNase B glycans was long suspected. The glycobiology pioneer Professor Akira Kobata, following data published almost 30 y ago reported, "... the structures of the sugar chains of ribonuclease $\mathrm{B}$ indicated that the removal of Man $\alpha 1-2$ residues in the processing step occurs randomly", [13]. In 1991 Lee's group using HPAE chromatography and PMPMP derivatization demonstrated extensive column heterogeneity beyond the classical $\mathrm{Man}_{5-9}$ GlcNAc glycomers [14]. Resolving such complexity was projected to invite insurmountable difficulties, e.g., ". . . the Isomer Barrier, a persistent technological barrier to the development of a single analytical method for the absolute characterization of carbohydrates ..." [15]. More specifically, "... the stereochemical blindness of mass spectrometry, product ions must first be separated based upon a physical principle that is not dependent upon $m / z$ before fragmentation." [16]. Such skepticism was based on "... a serious problem because they (isomers) yield sets of substructures after every round of dissociation where subsequent fragmentation of any given isolated ion $\mathrm{m} / \mathrm{z}$ furnishes identical product ion $m / z$ values" [17]. Clearly, the attributes of ITMS were not considered when these comments were drafted and although this report may challenge such reasoning, we claim no absolutes in structural characterization as we move ahead. However, it does appear that different isomeric structures will eventually provide an altered fragmentation pattern somewhere during disassembly. Anomeric differences in spectra have been observed, but a lack of chemically synthesized standards makes extensive claims inappropriate. Duplication of endproduct spectra pursued by different disassembly routes, spectral identity from different samples, preparations, and animal species brings some degree of confidence for a sequencing strategy that may be comprehensive.

An unfortunate aspect of much carbohydrate MS reporting is the conclusion that if you can not observe a difference MS/MS spectrum alternative structures are not present with the corollary that a tandem MS ap- proach supplies a comprehensive answer to structure; ". . . assignable to unambiguous sequences." Most wish carbohydrate sequencing would be that easy.

\section{Acknowledgments}

The authors acknowledge funding support from NIH-NIGMS RO1-GM54045, NCRR-RR-16459, and Glycan Connections, LLC, Lee, $\mathrm{NH} 03861$.

\section{References}

1. Costello, C. E.; Contado-Miller, J. M.; Cipollo, J. F. A Glycomics Platform for the Analysis of Permethylated Oligosaccharide Alditols. J. Am. Soc. Mass Spectrom. 2007, 18, 1799-1812.

2. Zhao, C.; Xie, B.; Chan, S. Y.; Costello, C. E.; O'Connor, P. B. Collisionally Activated Dissociation and Electron Capture Dissociation Provide Complementary Structural Information for Branched Permethylated Oligosaccharides. J. Am. Soc. Mass Spectrom. 2008, 19, 138-150.

3. Zhuang, Z.; Starkey, J. A.; Mechref, Y.; Novotny, M. V.; Jacobson, S. C. Electrophoretic Analysis of N-Glycans on Microfluidic Devices. Anal. Chem. 2007, 79, 7170-7175.

4. Ashline, D. J.; Lapadula, A. J.; Liu, Y. H.; Lin, M.; Grace, M.; Pramanik, B.; Reinhold, V. N. Carbohydrate Structural Isomers Analyzed by Sequential Mass Spectrometry. Anal. Chem. 2007, 79, 3830-3842.

5. Prien, J. M.; Huysentruyt, L. C.; Ashline, D. J.; Lapadula, A. J.; Seyfried T. N.; Reinhold, V. N. Differentiating N-Linked Glycan Structural Isomers in Metastatic and Nonmetastatic Tumor Cells Using Sequential Mass Spectrometry. Glycobiology 2008, 18, 353-366.

6. Zhang, H.; Singh, S.; Reinhold, V. N. Congruent Strategies for Carbohydrate Sequencing, II. FragLib: An MS ${ }^{n}$ Fragment Spectra Fingerprint Library. Anal. Chem. 2005, 77

7. Lapadula, A. J.; Hatcher, P. J.; Hanneman, A. J.; Ashline, D. J.; Zhang, H.; Reinhold, V. N. Congruent Strategies for Carbohydrate Sequencing. 3. OSCAR: An Algorithm for Assigning Oligosaccharide Topology from MS $^{n}$ data. Anal. Chem. 2005, 77, 6271-6279.

8. Ciucanu, I.; Kerek, F. A Simple and Rapid Method for the Permethylation of Carbohydrates. Carbohydr. Res. 1984, 131, 209-217.

9. Fu, D.; Chen, L.; O'Neill, R. A. A Detailed Structural Characterization of Ribonuclease B Oligosaccharides by 1H NMR Spectroscopy and Mass Spectrometry. Carbohydr. Res. 1994, 261, 173-186.

10. Guttman, A.; Pritchett, T. Capillary Gel Electrophoresis Separation of High-Mannose Type Oligosaccharides Derivatized by 1-Aminopyrene3,6,8-Trisulfonic acid. Electrophoresis 1995, 16, 1906-1911.

11. Vliegenthart, J. F. G. High Resolution H-1 Nuclear Magnetic Resonance Spectroscopy as a Tool in the Structural Analysis of Carbohydrates Related to Glycoproteins. Adv. Carbohydr. Chem. Biochem. 1983, 41, 209-374.

12. Kurimoto, A.; Daikoku, S.; Mutsuga, S.; Kanie, O. Analysis of EnergyResolved Mass Spectra at $\mathrm{MS}^{n}$ in a Pursuit to Characterize Structural Isomers of Oligosaccharides. Anal. Chem. 2006, 78, 3461-3466.

13. Liang, C. J.; Yamashita, K.; Kobata, A. Structural Study of the Carbohydrate Moiety of Bovine Pancreatic Ribonuclease B. J. Biochem. 1980, $88,51-58$.

14. Kakehi, K.; Suzuki, S.; Honda, S.; Lee, Y. C. Precolumn Labeling of Reducing Carbohydrates with 1 -(p-Methoxy)Phenyl-3-Methyl-5-Pyrazolone: Analysis of Neutral and Sialic Acid-Containing Oligosaccharides Found in Glycoproteins. Anal. Biochem. 1991, 199, 256-268.

15. Laine, R. A. Invited Commentary, Glyco-Forum. Glycobiology 1994, 4, 759-767.

16. Clowers, B. H.; Dwivedi, P.; Steiner, W. E.; Hill, H. H.; Bendiak, B. Separation of Sodiated Isobaric Disaccharides and Trisaccharides Using Electrospray Ionization-Atmospheric Pressure Ion Mobility-Time of Flight Mass Spectrometry. J. Am. Soc. Mass Spectrom. 2007, 16, 660-669.

17. Dwivedi, P.; Bendiak, B.; Clowers, B. H.; Hill, H. H. Jr. Rapid Resolution of Carbohydrate Isomers by Electrospray Ionization Ambient Pressure Ion Mobility Spectrometry-Time-of-Flight Mass Spectrometry (ESIAPIMS-TOFMS). J. Am. Soc. Mass Spectrom. 2007, 18, 1163-1175. 